\title{
Evaluation of Dielectric-Barrier-Discharge Actuator Substrate Materials
}

\author{
Stephen P. Wilkinson ${ }^{1}$ and Emilie J. Siochi ${ }^{2}$ \\ NASA Langley Research Center, Hampton, VA, 23681 \\ Godfrey Sauti ${ }^{3}$ and Tian-Bing $\mathrm{Xu}^{4}$ \\ National Institute of Aerospace, Hampton, VA, 23666 \\ Mary Ann Meador ${ }^{5}$ \\ NASA Glenn Research Center, Cleveland, OH, 44135 \\ Haiquan Guo ${ }^{6}$ \\ Ohio Aerospace Institute, Brookpark, OH, 44142
}

\begin{abstract}
A key, enabling element of a dielectric barrier discharge (DBD) actuator is the dielectric substrate material. While various investigators have studied the performance of different homogeneous materials, most often in the context of related DBD experiments, fundamental studies focused solely on the dielectric materials have received less attention. The purpose of this study was to conduct an experimental assessment of the body-force-generating performance of a wide range of dielectric materials in search of opportunities to improve DBD actuator performance. Materials studied included commonly available plastics and glasses as well as a custom-fabricated polyimide aerogel. Diagnostics included static induced thrust, electrical circuit parameters for 2D surface discharges and 1D volume discharges, and dielectric material properties. Lumped-parameter circuit simulations for the $1 D$ case were conducted showing good correspondence to experimental data provided that stray capacitances are included. The effect of atmospheric humidity on DBD performance was studied showing a large influence on thrust. The main conclusion is that for homogeneous, dielectric materials at forcing voltages less than that required for streamer formation, the material chemical composition appears to have no effect on body force generation when actuator impedance is properly accounted for.
\end{abstract}

\section{Introduction}

$\mathrm{A}$ LTERNATING current dielectric-barrier-discharge (DBD) actuators are flow-control devices that convert electrical to kinetic energy within a weakly ionized plasma over a dielectric surface. An illustration of a typical device operated with sinusoidal AC voltage is shown in Figure 1. The cyclical interaction between the alternately charged electrodes, dielectric surface and ionized air at the excitation frequency produces a zero-net-mass surface jet and a corresponding opposing mechanical reaction force on the model. Various other modes of operation are possible based on short duration, high amplitude voltage pulse technology ${ }^{1,2}$ and DC bias fields ${ }^{3}$ but are not discussed further in this report. The alternating current DBD actuator, henceforth referred to as simply a DBD actuator, has shown promise for a

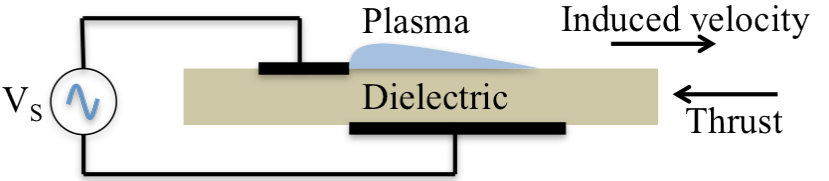

Figure 1. Conventional Alternating Current DBD configuration.

${ }^{1}$ Aerospace Engineer, Flow Physics and Control Branch, Mail Stop 170, AIAA Senior Member

${ }^{2}$ Aerospace Technologist, Advanced Materials and Processing Branch Mail Stop 397, Non-member

${ }^{3}$ Senior Research Scientist, 100 Exploration Way, Non-member

${ }^{4}$ Senior Research Scientist, 100 Exploration Way, AIAA Member

${ }^{5}$ Senior Research Scientist, Durability and Coatings Branch, MS 49-3, Non-member

${ }^{6}$ Senior Scientist, Durability and Coatings Branch, MS 49-3, Non-member 
boundary layer separation and aeroacoustic noise control areas. Excellent reviews of the DBD actuator are available and provide more detailed background information ${ }^{4,5}$.

With nearly two decades of in-depth study of the DBD actuator since its first modern study in aeronautics in $1995^{6}$, operation of the DBD actuator is now largely understood. The basic functioning of the electrical and fluid mechanical energy conversion mechanisms, actuator geometry requirements, sensitivities to gas composition and thermodynamic properties, electrical operating characteristics, numerical modeling methods, and much of the fundamental plasma chemistry is reasonably well understood. What is currently lacking are details of plasma chemical processes and dielectric surface interactions that are either difficult to access experimentally or are currently beyond the reach of practical numerical simulation capabilities. The current effort is a step towards identifying specifically where such knowledge gaps exist with the long-range goal of providing seed information for improvements in DBD technology.

The extent to which DBD performance can be improved is based on its underlying physics. The DBD is a threshold device in the sense that energy must be expended initially simply to ionize the working gas, usually air. No direct flow-control benefit is derived from that initial energy expenditure, at least in a momentum augmentation sense. Only after ionization has occurred, are charged particles available to do work on the surrounding nonionized gas via the local electric fields. It has been shown from measurements of electrical input power and induced momentum flux that the thermodynamic efficiency of the DBD actuator is actually very small, by at least one estimate less than $0.1 \%{ }^{7}$. This finding should be viewed with respect to the desired aeronautical applications. For high Reynolds number flight, the area of primary interest to NASA, a rough order-of-magnitude energy analysis shows that for a typical large transport aircraft, the average power required to overcome viscous drag is only about $1 / 4 \mathrm{watt} / \mathrm{cm}^{2}$ of total wetted surface area. (Estimate based on Boeing 737-200 at cruise conditions, operating weight $31600 \mathrm{~kg}$, total wetted area $769 \mathrm{~m}^{2}$, viscous drag assumed to be one half of total drag, speed $216 \mathrm{~m} / \mathrm{s}$, and $\mathrm{L} / \mathrm{D}=18$ ). Due to the low DBD thermodynamic efficiency, the required total energy input could easily exceed the object of the control, at least in the viscous drag case, if applied on an area wide basis. Proposed applications of the DBD are, therefore, generally discrete, local inputs such as those applicable to separation or noise control.

Another often cited metric of DBD performance is the interaction parameter ${ }^{8}$ based on energy density available in a DBD electric field compared to that in the flow:

$$
Z_{E H D}=\frac{\varepsilon_{0} E_{c a t h}^{2}}{2 \rho U^{2}}
$$

where $\varepsilon_{0}$ is the permittivity of free space, $\mathrm{E}_{\text {cath }}$ electric field at the cathode, $\rho$ air density, and $\mathrm{U}$ induced velocity. For expected electric field values, Reference 8 estimates maximum induced velocities in the approximate range of 2 $10 \mathrm{~m} / \mathrm{s}$, consistent with numerous laboratory observations. This estimate, along with the low electrical-to-kinetic conversion efficiency, further restricts DBD flow control options. Therefore, widespread application of DBD technology on high Reynolds number aircraft will require a significant increase in thermodynamic efficiency or discovery of creative applications for which energy input is not an overriding issue.

In the DBD actuator, the fundamental role of the dielectric is to enable a self-limiting discharge by preventing formation of conductive, gaseous, discharge channels between the electrodes that would circumvent the DBD electrohydrodynamic (EHD) forcing property. In terms of classical DC, low-pressure discharge tube terminology, the desired discharge is in the glow discharge region between corona formation and glow-to-arc transition. The externally imposed voltage causes dielectric polarization resulting in the appearance of surface charge on the exposed dielectric. The instantaneous magnitude of this charge depends upon the relative permittivity of the dielectric, the ionization physics in the gap including charge deposition on the surface and the time history of the excitation. This is illustrated in Figure 2 for the classical, one-dimensional case of a partially filled capacitor. Under the influence of the external power supply, $\mathrm{V}_{\mathrm{s}}$, the dielectric material of relative permittivity $\varepsilon_{\mathrm{r}}$ polarizes forming

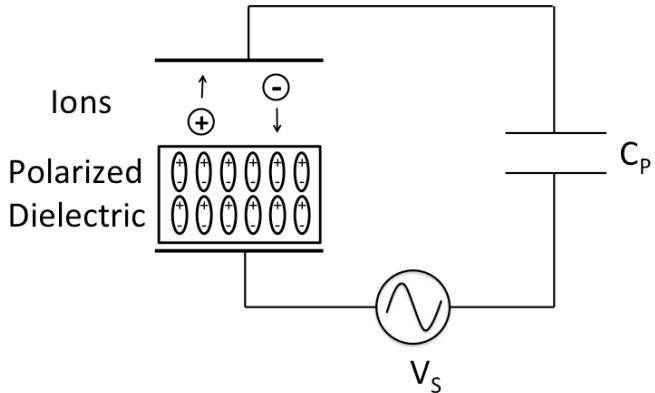

Figure 2. Illustration of limited breakdown ionization gap with dielectric material of relative permittivity $\varepsilon_{\mathrm{r}}$ and capacitor probe. alternating positive and negative charge layers on its surfaces.

The electric field due to the surface charge is responsible for the initial ionization of the air gap and the subsequent motion of the charge particles. The magnitude of the initial surface charge is determined by the relative 
permittivity of the dielectric material and the applied voltage. For the one-dimensional case shown, the surface charge prior to gas breakdown can be derived ${ }^{10}$ in terms of capacitance and applied voltage:

$$
C=\frac{Q}{V}=\frac{\varepsilon_{0} A}{t_{a}+\frac{t_{d}}{\varepsilon_{r}}}
$$

where $\mathrm{C}$ is capacitance, $\mathrm{Q}$ charge, $\mathrm{V}$ applied voltage, $\mathrm{A}$ plate area, $\mathrm{t}_{\mathrm{a}}$ air gap thickness and $\mathrm{t}_{\mathrm{d}}$ dielectric thickness. For a fixed geometry (i.e., $t_{a}, t_{d}$ and $A$ ), for the pre-breakdown case, the charge on the capacitor plates is solely dependent upon the relative permittivity. Following breakdown, charge deposition onto the surface ${ }^{11},{ }^{12}$ and remnant polarization from the previous AC cycle (memory effect ${ }^{13}$ ) also contribute to the surface charge. In addition to polarization and charge deposition, dynamic charged particle effects, such as secondary electron emission (SEE) due to ion bombardment are also a possibility although for the energy levels encountered in atmospheric DBD work, this may not be a significant effect. The Stoletow constant for air, the minimum energy required to create an ionelectron pair, is $81 \mathrm{eV} /$ ion-electron pair ${ }^{9}$. SEE data for glasses ${ }^{14}$ indicate a secondary electron yield of 2 or 3 electrons per incident electron with energy in the range of 300-450 eV. It is not clear whether this is close enough for a measureable effect in typical DBD work. The preface to the SEE data table in Reference 14 states that the SEE data is very sensitive to surface contamination so various controlled dielectric surface coatings could be an effective way to examine the relative importance of the SEE effect. Other possible effects include those related to: surface energy (hydrophilic vs. hydrophobic materials), surface conductivity (including semiconductor effects ${ }^{15}$ ), catalytic coatings $^{22}$, humidity and water absorption ${ }^{16,17}$, material electronegativity, and possibly others.

The dielectric loss-tangent plays an important role in dielectric heating, energy efficiency and physical durability of the material. This is an important research area for DBD material engineering. The data for small signal measurements will be reported in Section II. A related topic is partial discharges in high voltage dielectrics wherein the gas within microscopic voids in the material and breaks down leading to excessive heating and material failure ${ }^{18}$. The subject of nanoporous dielectrics (aerogels) and micro-porous dielectrics (foams) is also discussed.

The goal of this study was to attempt to explain performance differences among various, common dielectric materials. Where the data cannot be readily explained, opportunities exist for research and discovery with the potential for improvement of DBD actuator materials and/or actuator performance. The materials investigated in this study were those commonly found in DBD literature such as polymer plastics, glass and one case of boron nitride ceramic. We also had the unique opportunity to study newly developed polyimide aerogel materials ${ }^{19,20}$ for DBD application. Aerogels have dielectric constants close to unity and, as such, limit dielectric heating. Silica aerogel was previously examined in Reference 21 and it was found to have a potentially very high saturation thrust associated with formation of plasma streamers. In the current experiments, however, we did not have sufficient power supply voltage to reach the plasma streamer saturation state.

In addition to the basic dielectrics, we also initially intended to look at various surface coatings. The most notable example in that category is the work reported by Fine and Brickner ${ }^{22}$ which showed that a coating of photocatalytic nanoparticle titanium oxide can greatly increase the thrust of a DBD actuator. However, that work could not be replicated in two different laboratories (NASA Langley under the current study, and Princeton University by Profs. R. Miles and M. Post (personal communication)). What was found, however, is that atmospheric humidity can have a large, variable effect on DBD surface coatings, thus, the focus was shifted to study of humidity effects. Future investigations of surface coatings or infused layers with electrical properties may nonetheless be useful as suggested by their role in static charge elimination on dielecric surfaces ${ }^{23}$. Numerous coating options are available including anionic and cationic surfactants such as sodium dodecyl sulfate (SDS), sodium dodecylbenzenesulfonate (SDBS) and cetrimonium bromide (CTAB), and antioxidants such as $\alpha$ tocopherol (vitamin E) and 2,2-diphenyl-1-picrylhydrazyl (DPPH).

\section{Dielectric Measurements}

Real and imaginary permittivity measurements in the frequency range $10^{-2}-10^{6} \mathrm{~Hz}$ and temperature range $30-120^{\circ} \mathrm{C}$ were carried out using the combination of a Novocontrol Broadband Dielectric Converter (BDC) and Solartron SI1260 Impedance Gain/Phase Analyzer with a Novocool temperature controller. Data capture was managed by Novocontrol WinDETA software. Measurement samples were mounted in a Novocontrol BDS 1200 sample cell. 
Room temperature measurements were also made for samples mounted in a custom built PTFE lined cell to help determine and correct for sample cell related stray capacitances. All dielectric measurements were small signal measurements with an excitation voltage on the order of $1 \mathrm{~V}$.

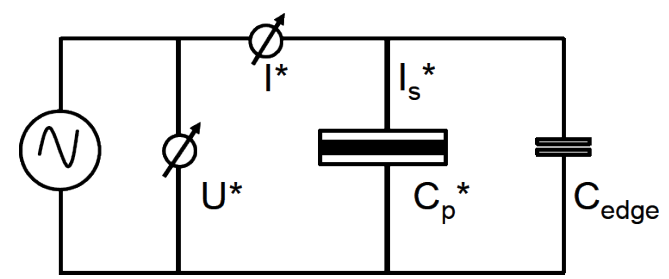

(a) Dielectric constant measurement

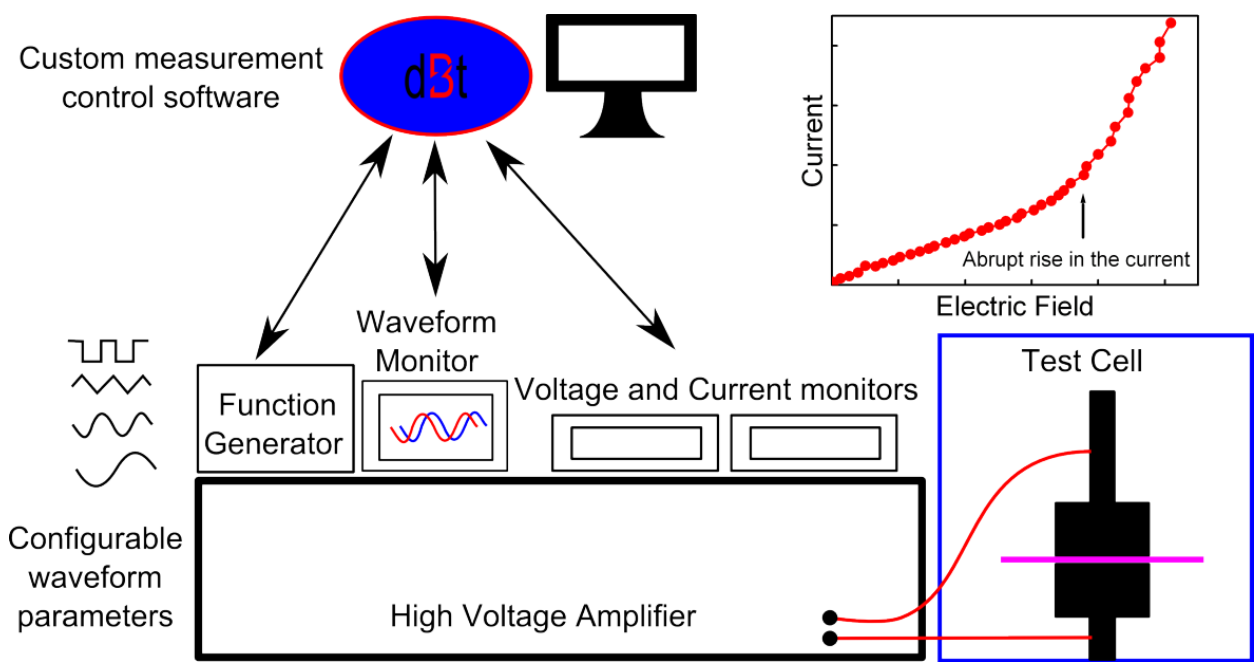

(b) Dielectric breakdown test

Figure 3. Schematic of the circuit for the dielectric constant measurements (a) and the setup for the dielectric breakdown strength measurements (b). Dielectric breakdown was established by monitoring the rise in the current through the dielectric.

Figure 3(a) shows the basic setup for a dielectric measurement. An excitation signal produced by the generator is applied to the sample and the complex voltage $U^{*}$ and the current $I^{*}$ as well as the phase shift between the current and the voltage are measured. The complex parallel capacitance of the sample $C_{p}^{*}$ is then

$$
C_{p}^{*}=-\frac{\mathrm{iI}{ }^{*}}{\omega U^{*}}-C_{\text {edge }}
$$

where $C_{\text {edge }}$ denotes the edge effects. For accurate measurements of the relatively low dielectric constants of the porous dielectrics, the edge correction was carried out using.

$$
C_{\text {corr }}=C_{\text {meas }}-\left(C_{\text {stray }}+C_{\text {edge }}\right)
$$

$C_{\text {stray }}$ was estimated by carrying out the measurements in different sample cells. $C_{\text {edge }}$ was determined using the following: 


$$
C_{e \text { dge }}=C_{0} \frac{2 d}{\pi D}\left[\ln \frac{8 \pi D}{d}-3+\mathrm{z}(x)\right]
$$

where $C_{0}=\epsilon_{0} \pi \frac{(D / 2)^{2}}{d}$ is the empty cell capacitance and $z(x)=(1+x) \ln (1+x)-x \ln x$ with $x=t / d$, $D$ the sample diameter, $d$ the sample thickness, $t$ the electrode thickness, and $\epsilon_{0}=8.85 \times 10^{-12} \mathrm{~F} / \mathrm{m}$ the permittivity of free space. The corrected dielectric constant is then $\epsilon_{\text {corr }}=\frac{C_{\text {corr }}}{C_{0}}$.

\section{A. Porous Dielectrics}

The dielectric breakdown strengths were measured for the porous dielectrics, polyetherimide microfoam and polyimide aerogels. The setup for dielectric breakdown testing consisted of a Philips PM5138A function generator, Trek 10/10B voltage amplifier $(10 \mathrm{kV}, 10 \mathrm{~mA})$, Keithley 2000 digital multimeter current monitors, and Hipotronics TF-2-50 2" (50 mm) diameter brass electrodes. Data capture was made using custom LabVIEW based dBt software. The tests were carried out according to ASTMD149 ${ }^{24}$. Mechanical tests were also carried out for the robust polyimide aerogel. Tensile tests were conducted using an Instron 5848 Microtester. The tensile test specimens had a gauge length of $10.00 \mathrm{~mm}, 5.08 \mathrm{~mm}$ width ( $\sim 30 \mathrm{um}$ thickness) and were strained at $10 \mathrm{~mm} / \mathrm{min}$. The tensile test was based on ASTM D $638^{25}$ and ASTM D $1708^{26}$.

Table 1 is a full listing of the dielectric materials studied including their chemical composition information. The materials chosen included some commonly used dielectrics as well well as novel formulations and porous materials. Recently it has been shown in the literature that silica aerogels can act as dielectrics for DBD actuators with high saturation thrusts ${ }^{21}$. More robust polyimide aerogels were used in the current study.

Table 1. Dielectric materials

(Aerogel: 50\% ODA/50\% DMBZ and BPDA with POSS crosslinks)

\begin{tabular}{|c|c|c|}
\hline $\begin{array}{c}\text { Trade (Common) } \\
\text { Name }\end{array}$ & $\begin{array}{c}\text { Chemical Name or } \\
\text { Class }\end{array}$ & Unit Formula \\
\hline Glass & Silica, Silicon Dioxide & $\mathrm{SiO}_{2}+\mathrm{Na}_{2} \mathrm{O}+\mathrm{CaO}$ \\
\hline Teflon $^{\circledR}$ (PTFE) & Polytetraflouroethylene & $\mathrm{C}_{2} \mathrm{~F}_{4}$ \\
\hline $\begin{array}{l}\text { Plexiglass }^{\circledR} \\
\text { (Acrylic, PMMA) }\end{array}$ & Polymethylmethacrylate & $\mathrm{C}_{5} \mathrm{O}_{2} \mathrm{H}_{8}$ \\
\hline Lexan $^{\circledR}$ & Polycarbonate & $\mathrm{C}_{18} \mathrm{H}_{20} \mathrm{O}_{3}$ \\
\hline ULTEM $^{\mathrm{TM}}$ & Polyetherimide & $\mathrm{C}_{37} \mathrm{H}_{24} \mathrm{O}_{6} \mathrm{~N}_{2}$ \\
\hline PEEK & Polyetheretherketone & $\mathrm{C}_{21} \mathrm{H}_{18} \mathrm{O}_{3}$ \\
\hline Kapton $^{\circledR}$ & Polyimide & $\mathrm{C}_{24} \mathrm{H}_{20} \mathrm{~N}_{2} \mathrm{O}_{5}$ \\
\hline Boron Nitride & Ceramic & $\mathrm{BN}$ \\
\hline Nylon- 6,6 & Polyamide & $\mathrm{C}_{12} \mathrm{H}_{22} \mathrm{~N}_{2} \mathrm{O}_{2}$ \\
\hline FVMQ & Fluorosilicone Elastomer & $\mathrm{C}_{9} \mathrm{H}_{22} \mathrm{O}_{3} \mathrm{~F}_{3} \mathrm{Si}_{3}$ \\
\hline Microfoam (PEI) & Polyetherimide & $\mathrm{C}_{37} \mathrm{H}_{24} \mathrm{O}_{6} \mathrm{~N}_{2}$ \\
\hline Aerogel & Polyimide & (see caption) \\
\hline
\end{tabular}




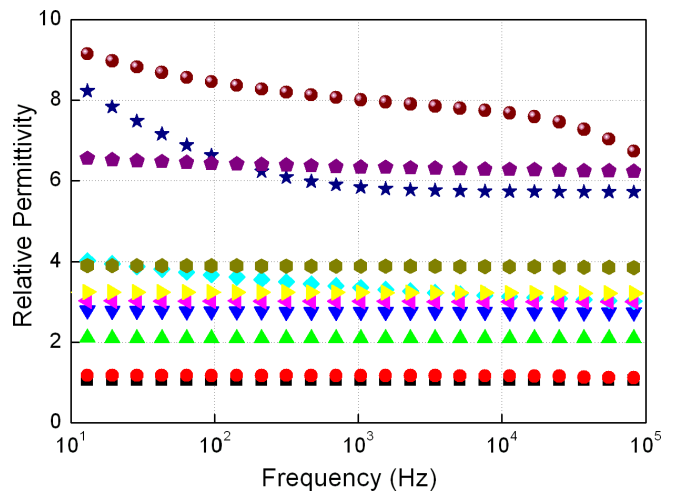

(a) Permittivity

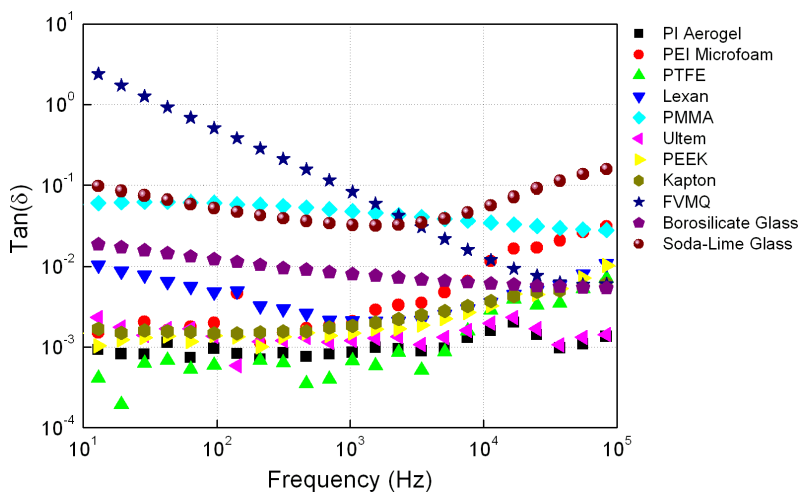

(b) $\operatorname{Tan}(\delta)$

Figure 4. Small signal dielectric constant and loss tangent at $30^{\circ} \mathrm{C}$.

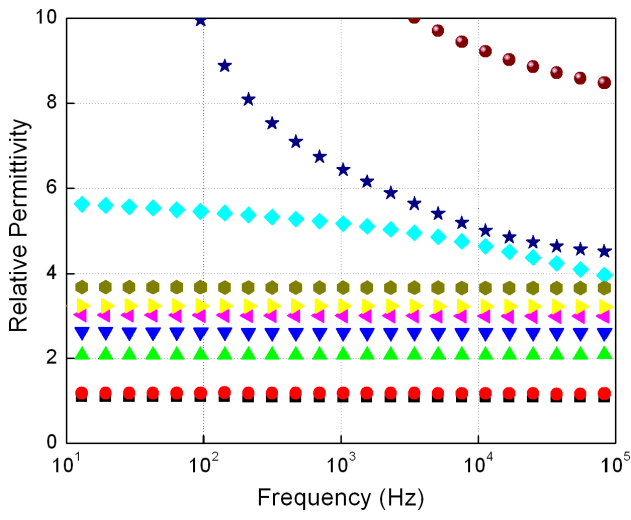

(a) Permittivity

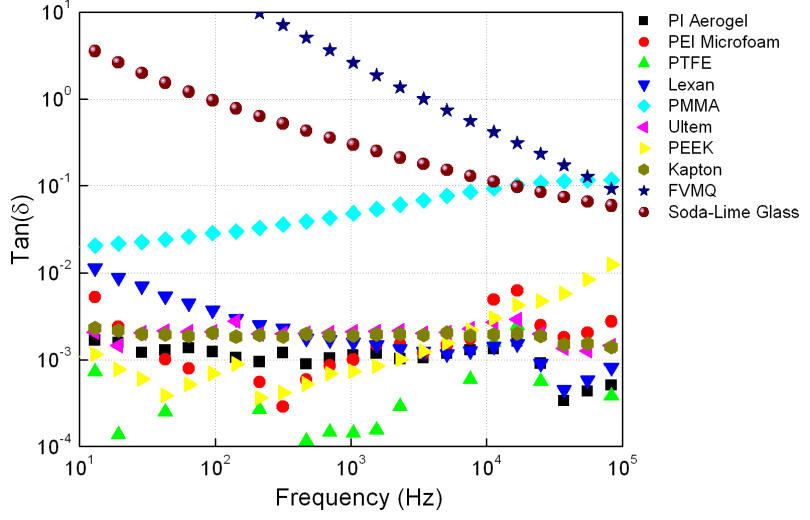

(b) $\operatorname{Tan}(\delta)$

Figure 5. Dielectric constant and loss tangent at $120^{\circ} \mathrm{C}$ for materials studied.

Figures 4(a) and 5(a) show the dielectric constants of the materials studied at 30 and $120^{\circ} \mathrm{C}$, respectively and the frequency range of interest for DBD actuators. The aerogel and microfoam have very low and non-dispersive dielectric constants that are close to 1 . Glass has the highest and most frequency dependent dielectric constant. The remainder of the dielectrics show largely non-dispersive dielectric constants between the porous dielectrics and the glass. At $120^{\circ} \mathrm{C}$, the dielectric constants of the aerogel and microfoam remain largely unchanged while those of PMMA and glass change very significantly. The aerogel and microfoam are polyimides, polymers with high glass transition temperatures $\left(\mathrm{T}_{\mathrm{g}}\right)$ and thus have low sensitivity of the dielectric constant to the temperature. Ion mobility in the glass is expected to be the main contributor to the very high and dispersive dielectric constant ${ }^{27}$. Figures 4(b) and 5(b) show the loss tangents of the materials. Again the glass shows the highest loss while the PI aerogel and PTFE show the lowest. It should be noted though that the loss of the microfoam is slightly higher than that of both PTFE and the PI-aerogel which indicates a slightly conductive matrix for the microfoam.

Figure 6 shows the leakage current as a function of applied electric field for the high voltage breakdown tests of the porous dielectrics. The leakage current for the microfoam rises rapidly with the increasing electric field making it unsuitable for DBD applications. This is a result of the slight conductance of the foam matrix and internal breakdown within the relatively large pores. For the aerogels, the pore size is small enough such that internal breakdown does not occur ${ }^{28}$ allowing the current to rise steadily. Two formulations of aerogel were tested, a flexible aerogel containing hydrophilic chemical groups (ODA and BPDA with POSS crosslinks) and a more hydrophobic composition (50\% ODA / 50\% DMBZ and BPDA with POSS crosslinks). For the aerogel with the hydrophilic groups, dielectric breakdown occurs at an electric field of about $10 \mathrm{kV} / \mathrm{mm}$ as indicated by the abrupt rise in the 
leakage current (Figure 6, PI Aerogel 1). The hydrophobic aerogel remained insulating to the limit of the breakdown testing and this formulation was used in subsequent mechanical and DBD testing.

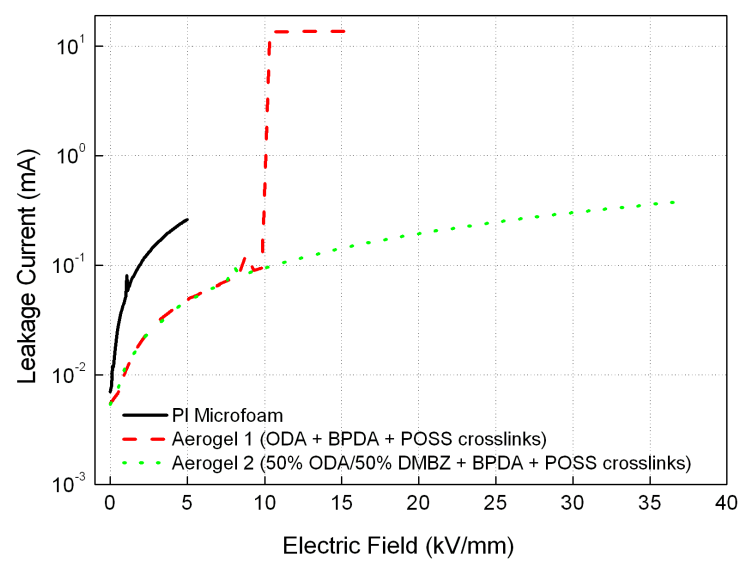

Figure 6. Leakage current vs. applied electric field from the dielectric breakdown testing of the porous dielectrics.

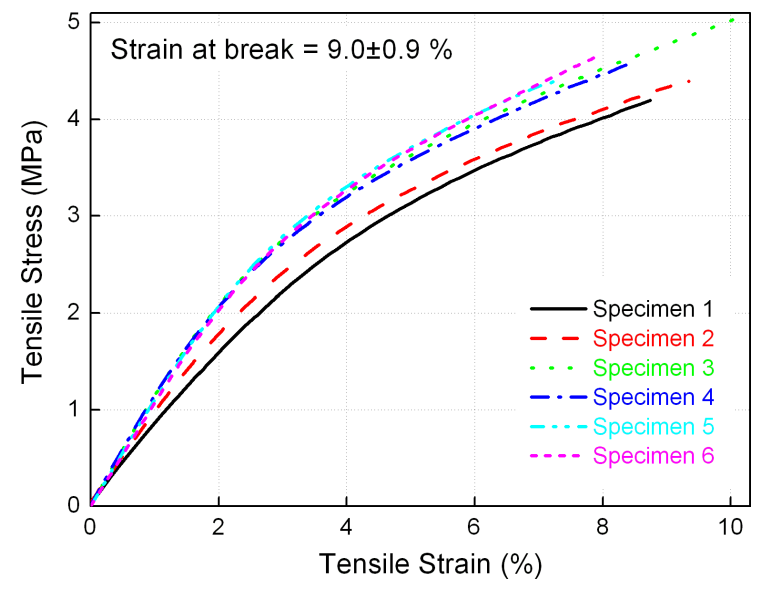

Figure 7. The stress-strain curves from mechanical tests of the polyimide aerogel.

Figure 7 shows the tensile properties of a series of the hydrophobic aerogel specimens. It can be seen that unlike the highly brittle and friable silica aerogels used in Reference 21 , this material is highly robust with the strain at break of $10 \%$. Thus this material can act as a high saturation thrust, low mass and robust DBD dielectric. 


\section{Static Thrust Stand Measurements}

\section{A. Test Apparatus and Models}

Performance characterization of the dielectric materials was conducted using two methods: static thrust measurements discussed in this section (III) and, one-dimensional volume-discharges using the charge transfer method discussed in Sections II and V. A photograph of the thrust stand is shown in Fig. 8.

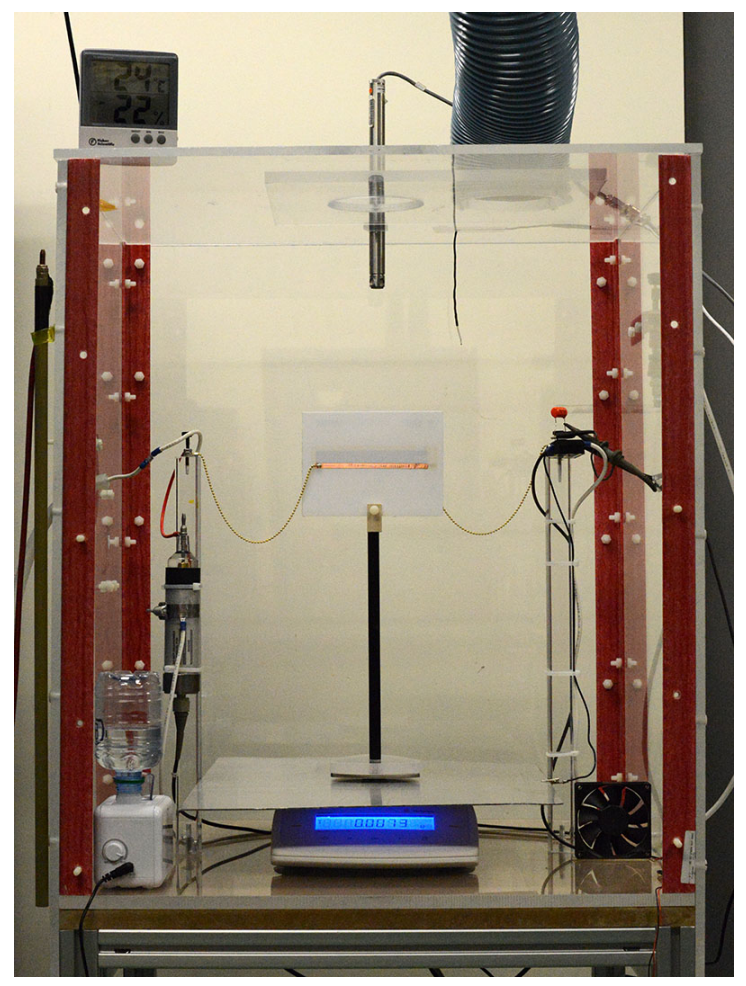

Figure 8. Photograph of DBD thrust measurement apparatus.

An electronic mass balance was used to measure DBD thrust force. It had a full scale rating of 310 grams and a resolution of 0.1 milligram. The device body was of all metal construction and was electrically grounded (including the metal platen). No additional shielding was required to avoid EMI effects from the high voltage power supply and plasma. The acrylic plastic enclosure's volume was $61 \times 61 \times 71.1 \mathrm{~cm}(24 \times 24 \times 28$ inch) with $9.5 \mathrm{~mm}(3 / 8$-inch) wall thickness and allowed adequate distance between the DBD actuator and sidewalls of the enclosure to avoid significant electrostatic induction force errors. The red corner posts shown in Figure 8 are electrical grade GP03 fiberglass 90-degree structural angle assembled with nylon machine screws. The floor is $19 \mathrm{~mm}(3 / 4$ inch) thick wood medium density fiberboard (MDF). The ground plane was aluminum foil bonded to $3 \mathrm{~mm}(0.12$ inch) thick acrylic plastic sheet. Its main function was to provide additional protection for the grounded force balance in the event that the energized model would fall. Its effect on the electric field distribution within the enclosure was not examined. The model standoff post was $12.5 \mathrm{~mm}(0.492 \mathrm{inch})$ square acrylic mounted in a plastic foam block.

A photograph of a typical DBD actuator used for thrust measurement is shown in Figure 9(a) and critical dimensions are described in Figure 9(b) and Table 2. The dielectric thickness varied with material as supplied by the manufacturer. Only manufacture's stock thicknesses were used and no attempt was made to alter the thickness out of concern for modifying the surface properties. The electrodes were $0.075 \mathrm{~mm}(0.003$ inch $)$ copper adhesive tape (including adhesive). The exposed electrode was $5 \mathrm{~mm}(0.197 \mathrm{inch})$ wide and the buried electrode $15 \mathrm{~mm}(0.591$ inch) wide with zero overlap. Scotch ${ }^{\mathrm{TM}} 130 \mathrm{C}$ electrical splicing tape was used to prevent plasma breakdown on the backside of the models. Power leads, consisting of \#3 yellow brass ball chain (3/32 inch diameter, 94 balls/foot) or \#27 AWG (American Wire Gage) (7 twisted strands of \#35 AWG tinned copper wire with a flexible, soft plastic 
jacket of unknown material) were soft-soldered to the copper electrodes. The ball chain exhibits very high impedance, on the order of $500 \mathrm{MOhm}$, when measured with a typical low voltage bench resistance meter. In operation, however, there is little or no discernible difference in the charge transfer cyclogram between the ball chain and solid wire indicating a similar lack of difference in the induced thrust. The reason is most likely that the multiple contact resistances due to the individual brass balls and connecting wire links breakdown microscopically under high voltage thereby substantially lowering the overall resistance. This could be verified by measuring the high voltage impedance of the chain under vacuum however such test was not conducted. It does, however, raise a caution if the ball chain were to be used for comparing thrust data at different ambient pressures.

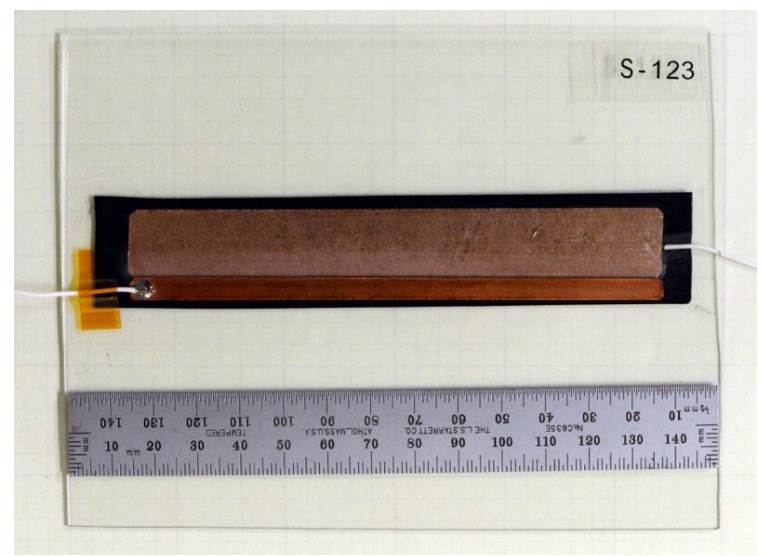

(a)

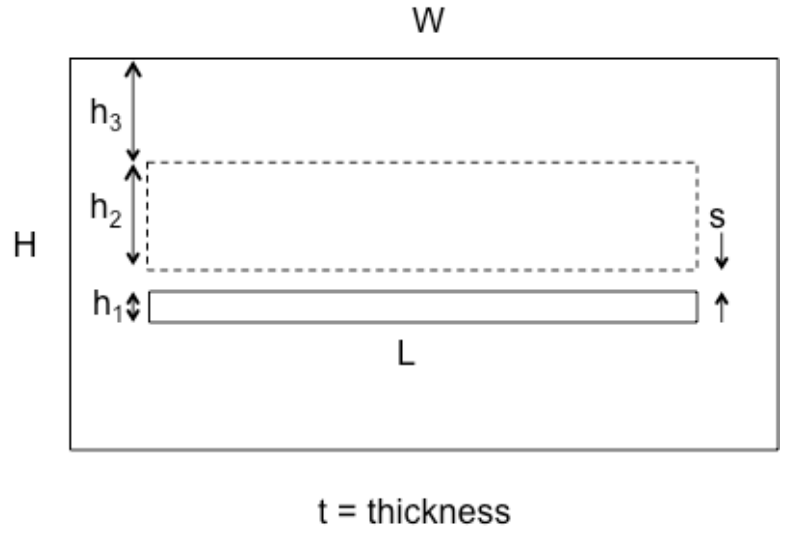

(b)

Figure 9. (a) Photograph of typical DBD thrust measurement model, (b) Dimensional schematic.

Table 2. DBD thrust model dimensions.

\begin{tabular}{|c|c|c|c|c|c|c|c|c|c|c|}
\hline Model & Material & H & $\mathbf{W}$ & $\mathbf{t}$ & h1 & h2 & h3 & $\mathbf{L}$ & $\mathbf{s}$ & $\begin{array}{c}\text { Plasma } \\
\text { Initiation } \\
\mathrm{kVpp} / \mathrm{kHz}\end{array}$ \\
\hline S108 & Acrylic (PMMA) & 124 & 197 & 2.0 & 5 & 15 & 61 & 150 & $\mathbf{0}$ & $6.3 / 5$ \\
\hline S109 & $\begin{array}{l}\text { Polycarbonate } \\
\text { (Lexan) }\end{array}$ & 120 & 203 & 2.3 & 5 & 15 & 60 & 150 & $\mathbf{0}$ & $6.6 / 5$ \\
\hline S110 & Ultem & 120 & 153 & 3.2 & 5 & 15 & 60 & 124 & $\mathbf{0}$ & $6.9 / 5$ \\
\hline S111 & PEEK & 116 & 153 & 3.1 & 5 & 15 & 58 & 120 & $\mathbf{0}$ & $7.6 / 5$ \\
\hline S113 & Glass & 104 & 153 & 1.2 & 5 & 15 & 57 & 120 & $\mathbf{0}$ & $5.6 / 5$ \\
\hline S114 & PTFE (Teflon) & 120 & 153 & 3.3 & 5 & 15 & 60 & 113 & $\mathbf{0}$ & $8.6 / 5$ \\
\hline S118 & Boron Nitride & 102 & 152 & 7.3 & 5 & 15 & 50 & 120 & $\mathbf{0}$ & $7.3 / 5$ \\
\hline
\end{tabular}

Supply voltage was recorded with a Tektronix model P6015 high voltage probe mounted inside of the test enclosure on the left-hand tether post in Figure 8. Current was measured using two methods. One was with a current monitor transformer (Pearson Electronics, Model 2100) with a high frequency cutoff rating of $20 \mathrm{MHz}(-3 \mathrm{~dB})$ and a sensitivity of 1 volt/amp. It was situated on the left side of the test enclosure in Figure 8 where the power lead passes through the acrylic wall. The second method was to use the probe capacitor and charge transfer method described in Section IV. 
Accuracy of DBD thrust measurements using a mass balance was a concern throughout the test process. Ashpis and Laun ${ }^{29}$ have identified numerous sources of error that can alter thrust measurements and need to be accounted for including: new model plasma burn-in duration, time between measurements (i.e., model rest period), data settling time after a voltage change, exposed electrode distance upstream from model edge, dielectric polarization remnant effects, mechanical forces due to lead wire elasticity, ion wind effects from corona on lead wires, electrostatic induction forcing due to capacitive coupling surroundings, electrode size and placement inaccuracies, measures to prevent undesired regions of plasma breakdown (corona dopes and tapes), power supply impedance matching issues, and variable, uncontrolled atmospheric humidity.

\section{B. Humidity Effects}

The last item, humidity, is of particular concern since it can affect DBD performance via multiple pathways, i.e., through charge effects on polar water molecules, charge effects on water impurities, plasma chemistry reactions involving water, modification of air density (binary gas), water adsorption/absorption effects on the dielectric, surface condensation, and dielectric surface conductivity. Also, depending on how the humidity is created, an airborne dispersion of microscopic water droplets can be created with uncertain effects on the plasma and DBD thrust measurements. Humidification methods, other than naturally occurring atmospheric humidity, include thermal evaporation and various methods of atomization including jet nebulizers and ultrasonic humidifiers. Kwok ${ }^{30}$ has shown that a small charge can be imparted even to distilled water droplets depending on the atomization method used.

To demonstrate the difficulty with humidity, two dielectric materials were tested having widely different water retention properties, PTFE and Nylon 6,6. PTFE has an extremely low water absorption rate, $<0.01 \%$ weight gain for 24-hour immersion per ASTM D-570 $0^{31}$. Its also has one of the lowest surface energies of all polymer plastics. Nylon 6,6 on the other hand is known for its hygroscopic nature with a ASTM D-570 water weight gain of about 3\% and a surface energy at least double that of PTFE. Figure 10(a) shows the PTFE DBD thrust response

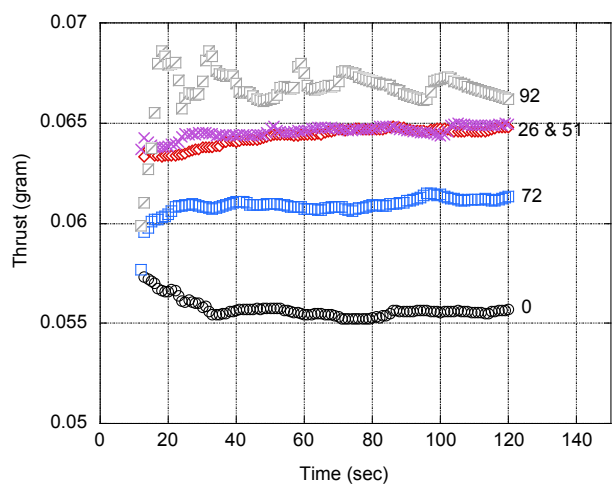

(a) PTFE

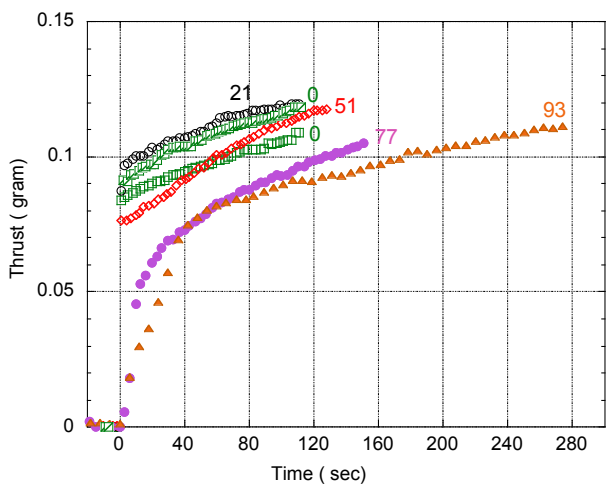

(b) Nylon 6,6

Figure 10. DBD model thrust data with variable humidity. Both models excited with step input of $20 \mathrm{kVpp}, 1 \mathrm{kHz}$ (sine). (a) $1.07 \mathrm{~mm}$ thick PTFE dielectric, (b) $0.97 \mathrm{~mm}$ thick nylon 6,6 dielectric. For the nylon case only, 0-1 denotes the pre-run $0 \%$ humidity and $0-2$ post-run $0 \%$ humidity.

for five levels of humidity created by ultrasonic humidification in the test enclosure (Figure 8 ). The $0 \%$ relative humidity case was obtained by displacing the room air in the test enclosure with a steady flow of dry air from a dual regenerative desiccant drier (Hankison Model DHW7) with a specified output dew point temperature of -70 deg F. Prior to thrust measurement, the dry airflow was stopped and the enclosure sealed. For the conditions described in the caption, the thrust levels are seen to increase with increasing humidity. The erratic appearance of the $92 \%$ case is most likely related to surface condensation. Figure 10(b) shows the Nylon 6,6, case for the same electrical input conditions. In this case, increasing humidity tends to reduce thrust except for the $\mathrm{RH}=21 \%$ case. Also note that the pre-run and post-run $0 \%$ cases did not repeat well for reasons most likely related to insufficient drying time. The continual rise in thrust with time for the Nylon dielectric is an additional notable difference and no explanation can be offered at this time. The lesson from this test, besides the fact that Nylon is probably a poor DBD dielectric choice, is that humidity has a major impact on DBD performance affecting both trend and amplitude. Control of humidity in DBD testing is an essential requirement where high accuracy results are required. 


\section{Thrust Measurements}

Thrust measurements, scaled with respect to electrode length, are shown in Figure 11 for eight different dielectric materials covering nearly an order of magnitude in thickness and permittivity as indicated in the legend. (These data were acquired prior to the humidity testing discussed above and accurate humidity data was not recorded. Testing was conducted in a climate-controlled laboratory with seasonal relative humidity variations typically in the range of $30-50 \%$.) In log-log coordinates, the curves are approximately parallel to each other. This suggests that the plasma and surface charge growth responsible for the increase in thrust behave in the same fashion independently of the chemical composition of the dielectric material.

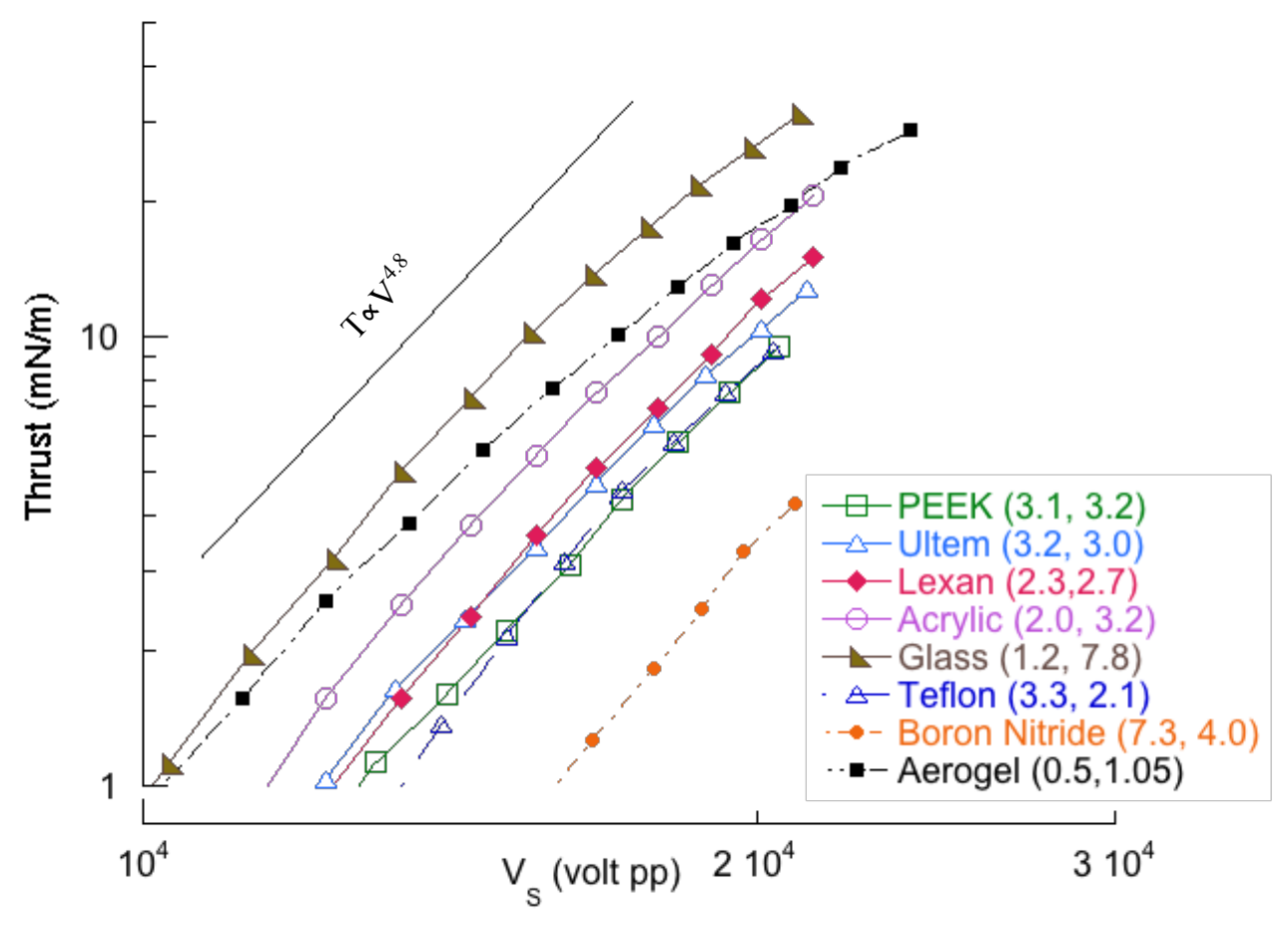

Figure 11. DBD thrust data for dielectric materials. Frequency $=5 \mathrm{kHz}$ (sine input). The number pairs in the legend refer to the material thickness in millimeters and dielectric coefficient respectively. Solid line $T \propto V^{4.8}$ is for reference.

Figure 12 shows a cross plot of the thrust data in Figure 11 at a constant voltage of $18 \mathrm{kV}$ with respect to the 1D effective thickness, $\mathrm{t}_{\mathrm{d}} / \mathcal{E}_{\mathrm{r}}$ in semi-log coordinates. The $18 \mathrm{kV}$ is simply convenient value that vertically intersects all of the thrust curves. Figure 12 shows that the thrust varies as the inverse $\log$ of the effective thickness, $t_{d} / \varepsilon_{r}$. 


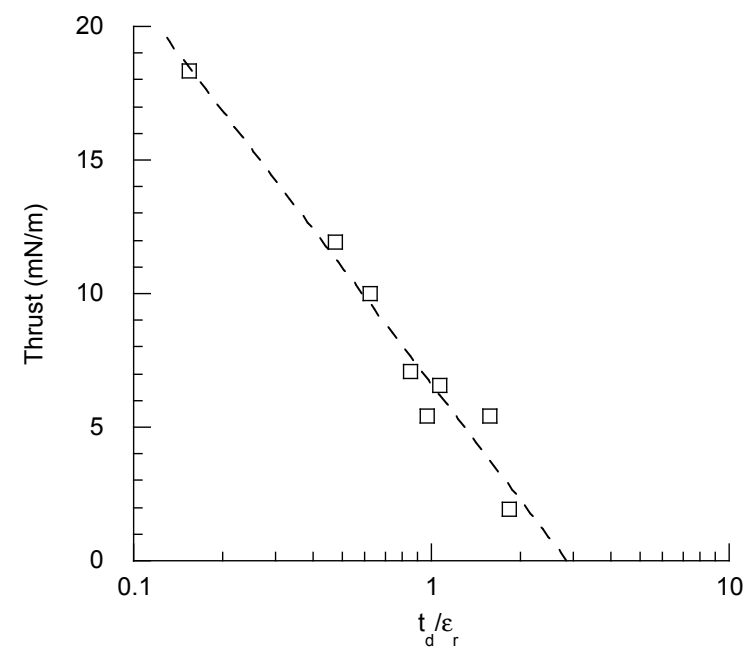

Figure 12. Cross-plot of thrust in Figure 11 at a constant input voltage, $V_{s}=18 \mathrm{kV}$, with respect to the effective dielectric thickness, $t_{d} / \varepsilon_{\text {r }}$.

The most probable cause of this semi-logarithmic behavior is the variation in circuit impedance with dielectric thickness and permittivity. This conjecture can be assessed by examining theoretical formulations of the prebreakdown impedance of an asymmetric actuator or the closely related symmetric case. A simple and exact solution is available for the canonical case of a small diameter cylinder above a conducting plane in a region of constant dielectric constant using the method-of-images ${ }^{32,35}$, a graphical method for solving Poisson's equation. The relevant physical case would be that of a circular wire on an aerogel dielectric with unity dielectric constant. As will be shown below, this model captures the semi-logarithmic behavior shown in Figure 12 thereby largely proving the circuit impedance effect.

Figure 13 shows a symmetric, two-dimensional slice of the electric field distribution along a wire suspended above a plane obtained using the method-of-images ${ }^{35}$. A rectangular, shaded region of thickness $t_{d}$ is shown to demarcate the physical boundaries of a dielectric with unity dielectric constant $\left(\varepsilon_{\mathrm{r}}=1\right)$, for example an aerogel. Since such a dielectric does not bend the electric field lines at the air-dielectric interface, as would higher valued permittivity materials, it does not affect the solution.

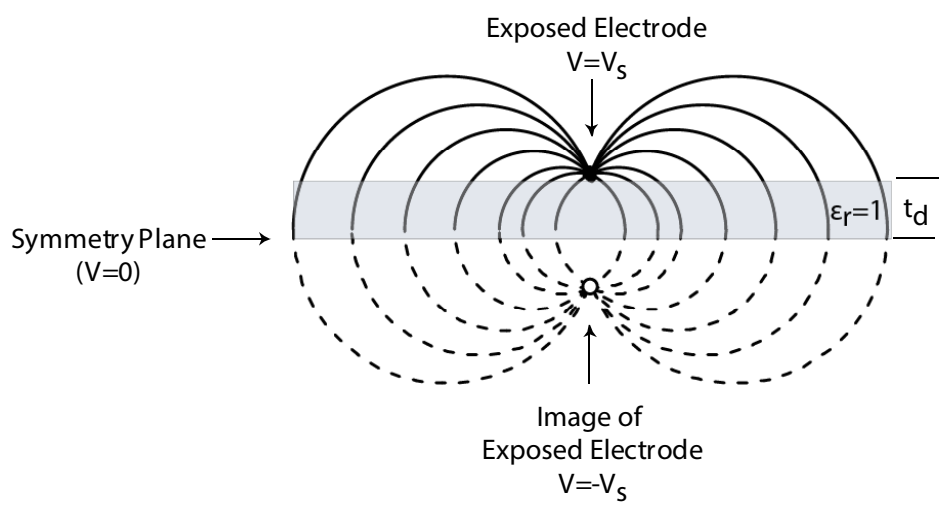

Figure 13. Method of images for a cylinder above a ground plane.

The top, exposed electrode of radius $r$ is shown as a filled circle on the upper surface of the dielectric. The image electrode is shown below the line of symmetry by an equal distance as an open circle. The E-field flux lines are represented by circles with centers on the line of symmetry and passing through the top electrode and its image. 
Figure 14 shows one-half of the method-of-images geometry portrayed in Figure 12 with the flux lines removed for clarity. The potential at any point with respect to the symmetry plane $(V=0)$, in this case $V_{p}$ on the upper surface of the dielectric, can be obtained by

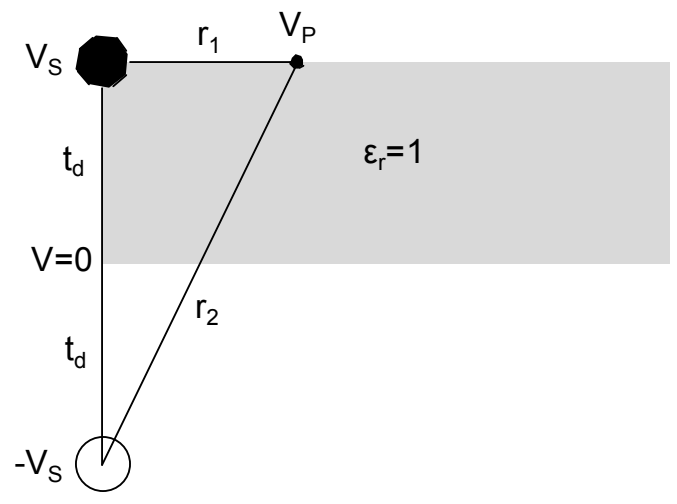

Figure 14. Expanded view of right side of Figure 13 without field lines.

integrating the electric fields emanating from the two electrodes and using the principle of superposition. Both Attwood (Reference 32, pages 85-88, 141-145) and Hyatt (Reference 35, pages 150-155, 390-393) present the derivation in detail. Assuming that the electrodes' diameter and the distance to the evaluation point $\mathrm{P}$ are each much less than the dielectric thickness, the surface volatge at point $\mathrm{P}$ is approximated by the expression:

$$
V_{p}=\frac{\rho_{s}}{2 \pi \varepsilon} \ln \frac{r_{2}}{r_{1}} \approx \frac{\rho_{s}}{2 \pi \varepsilon} \ln \left(\frac{2 t_{d}}{r_{1}}\right)
$$

where $\rho_{\mathrm{s}}$ is the lineal charge density on the electrode due to the applied voltage, $\mathrm{V}_{\mathrm{s}}$, and $\varepsilon$ is the permittvity of the medium, assumed to be unity in this case.

Equation (6) shows that for a fixed location on the dielectric surface close to the upper electrode $\left(r_{1}\right)$, the voltage $\mathrm{V}_{\mathrm{p}}$ increases logarithmically with dielectric thickness. As $\mathrm{V}_{\mathrm{p}}$ increases, however, the voltage difference $\Delta \mathrm{V}=\mathrm{V}_{\mathrm{s}}-\mathrm{V}_{\mathrm{p}}$ decreases. Since the voltage difference, $\Delta \mathrm{V}$, drives the momentum transfer between the ionized gas particles and the neutral gas, a thicker dielectric tends to reduce induced thrust logarithmically at constant input votage. Following Attwood's development ${ }^{32}$, the origin of the logarithmic response is ultimatley the integration of the E $\propto 1 / \mathrm{r}$ radial electric field required for derivation of the potential field. Figure 12 clearly shows an inverse logrithmic response to the dielectric thickness. While this derivation has been for the case of unity dielectric constant, the results clearly apply to the general case of non-unity dielectric constant as shown by the correlation to the effective thickness $t_{d} / \varepsilon_{\mathrm{r}}$ in Figure 12. The effective thickness term appears explicitly in the expression for the capacitance of parallel plate capacitor, $\mathrm{C} \propto \varepsilon_{\mathrm{r}} / \mathrm{t}_{\mathrm{d}}$ or the capacitive impedance $\mathrm{Z} \propto 1 / \mathrm{C} \propto \mathrm{t}_{\mathrm{d}} / \varepsilon_{\mathrm{r}}$ and appears to be a useful correlating parameter in the general case. This result establishes that thrust level variations shown in Figure 11 are due to pre-breakdown circuit impedance. More specifically, it shows that the thrust variation at constant input voltage is due to dielectric polarization, the physical mechanism for the impedance variation. Reference 34 presents a derivation of the exact solution for the potential between concentric cylinders that also shows the logarithmic radial variation.

Wheeler ${ }^{33}$ has investigated the characteristic impedance of printed circuit board traces, also referred to as strip lines or microstrips that could also function as symmetric DBD actuators. Some of the original DBD work used exactly that construction technique ${ }^{6}$. Wheeler developed a lengthy, approximate expression for the characteristic impedance of the microstrip in terms of its geometry and the dielectric constant of the circuit board material. Based on equations 10, 13 and 21 in Reference 33, the characteristic impedance is: 


$$
\begin{aligned}
& \frac{Z}{Z_{0}}=\frac{0.113}{\sqrt{\varepsilon_{r}+1}} \ln \left\{1+\left(\frac{4 t_{d}}{w_{\text {eff }}}\right)\left[\left(\frac{14+8 / \varepsilon_{r}}{11}\right)\left(\frac{4 t_{d}}{w_{\text {eff }}}\right)+\sqrt{\left.\left.\left(\frac{14+8 / \varepsilon_{r}}{11}\right)^{2}\left(\frac{4 t_{d}}{w_{\text {eff }}}\right)^{2}+\frac{1+1 / \varepsilon_{r}}{2} \pi^{2}\right]\right\}}\right.\right. \\
& w_{\text {eff }}=w+t \frac{\left(1+\frac{1}{\varepsilon_{r}}\right)}{2 \pi} \ln \left(\frac{4 e}{\sqrt{\left(\frac{t}{t_{d}}\right)^{2}+\left(\frac{1}{\pi} \frac{1}{\left(\frac{w}{t}+\frac{11}{10}\right)}\right)^{2}}}\right)
\end{aligned}
$$

where $\mathrm{Z}$ is the characteristic impedance, $\mathrm{Z}_{0}$ impedance of free space $(377 \mathrm{ohm})$, $\varepsilon_{\mathrm{r}}$ dielectric constant, $\mathrm{t}_{\mathrm{d}}$ dielectric thickness, $w_{\text {eff }}$ microstrip effective width, w actual microstrip width, $t$ microstrip thickness and e natural logarithm base.

Figure 15 shows a plot of Wheeler's charateristic impedance ratio, $\mathrm{Z} / \mathrm{Z}_{0}$, with respect to effective dielectric thickness, $\mathrm{t}_{\mathrm{d}} / \varepsilon_{\mathrm{r}}$, for a constant electrode width and thickness of the materials tested in this study. The plot shows that the actuator impedance is linearly related to the effective thickness for the range of values studied so that the same logarithmic thrust response to dielectric thickness would be expected. A similar, approximate agrument can be made for the characteristic impedance of a planar transmission line (Hyatt ${ }^{35}$, page 392). At constant inductance and neglecting the resistivity and conductance of the dielectric material, the capacitance is proportional to the reciprocal of the square of the characteristic impedance (Reference 35, page 385). For an asymmetric DBD actuator, the capacitance would be one-half of that value. This supports the finding that the effective dielectric thickness properly correlates the thrust differences due to pre-breakdown impedance variation.

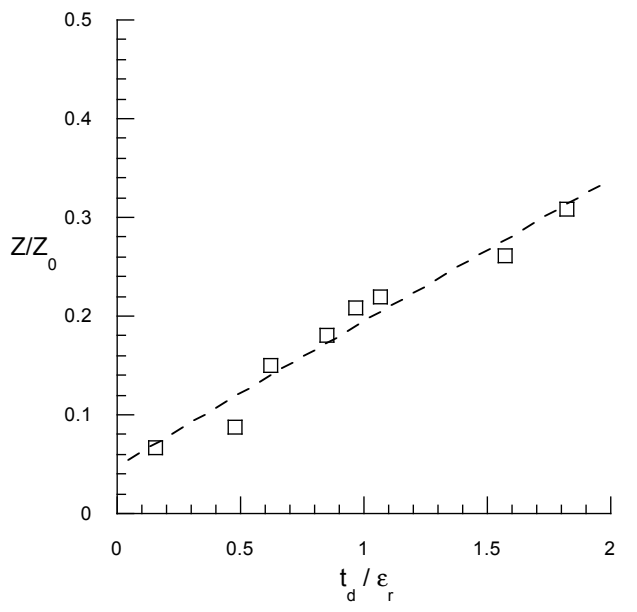

Figure 15. Wheeler impedance formula ${ }^{33}$ vs. effective thickness at constant electrode width $(\mathrm{w}=5 \mathrm{~mm})$ and electrode thickness $(0.1 \mathrm{~mm})$.

Another approach to assessing the thrust curves in Figure 11 is to consider the DBD actuator as a capacitive voltage divider $^{34}$ and as shown in Figure 16. The plasma is modeled as lumped-parameter capacitive and resistive 
elements, $\mathrm{C}_{\mathrm{a}}$ and $\mathrm{R}_{\mathrm{a}}$ that will assume different values depending on whether the plasma is on or off. The high AC voltage is denoted by $\mathrm{V}_{\mathrm{s}}$. In the current discussion, the plasma is assumed to be on.

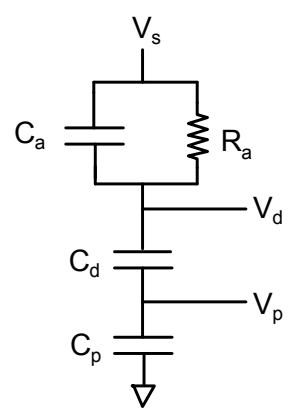

Figure 16. Simplified circuit representation of DBD actuator.

The capacitance $C_{d}$ represents the capacitor formed by the exposed and buried electrodes across the dielectric material. $\mathrm{V}_{\mathrm{d}}$ is the voltage on the virtual electrode of the exposed dielectric surface and the difference $\Delta \mathrm{V}=\mathrm{V}_{\mathrm{s}}-\mathrm{V}_{\mathrm{d}}$ is the potential difference that drives the plasma particles to produce the DBD thrust. Capacitance $\mathrm{C}_{\mathrm{p}}$ is a constant and is used for charge transfer measurements. For the current discussion, it is considered it to be a short circuit, i.e. $\mathrm{C}_{\mathrm{p}}=\infty$, that effectively removes it from the circuit. Solving the voltage divider for $\mathrm{V}_{\mathrm{d}}$ yields:

$$
\frac{V_{d}}{V_{s}}=\frac{X_{d}}{X_{a}+X_{d}}
$$

where $X_{d}$ and $X_{a}$ are the complex impedances of the dielectric and air plasma respectively. $X_{a}$ can be expressed algebraically in terms of the parallel components $C_{a}$ and $R_{a}$ but for current purposes, that step is not necessary. The key observation is that, if the role of the dielectric in thrust production is desired, that implies a relationship between the surface potential $\left(\mathrm{V}_{\mathrm{d}}\right)$ and the air plasma impedance $\left(\mathrm{X}_{\mathrm{a}}\right)$ with the supply voltage $\left(\mathrm{V}_{\mathrm{s}}\right)$, and the dielectric impedance $\left(\mathrm{X}_{\mathrm{d}}\right)$, held constant. In other words, to prove or disprove a plasma-surface interaction effect on thrust, data must be compared at constant dielectric impedance and supply voltage. This is essentially the same conclusion arrived at using the impedance arguments based on the method-of-images and Wheeler's characteristic impedance formula.

\section{One-Dimensional Volume Discharge Electrical Measurements}

As noted in the Introduction, the 1D volume discharge may offer a simple alternative to the asymmetric DBD geometry in a search for DBD plasma-surface interaction effects. The goal of the current 1D work was to develop such experimental capability, along with related data analysis methods, in order to explore its diagnostic value for DBD materials study. Figure 17 illustrates the similarities between 1D and 2D cases. As in the 2D case, when the 1D geometry is operated at a sufficiently high voltage, ionization occurs in the air gap and the resulting plasma is commonly referred to as a volume discharge. For the surface discharge, the plasma initiates at the exposed electrode edge and sweeps across the dielectric surface above the buried electrode, varying the overall device capacitance due to both spatial and temporal plasma mechanisms ${ }^{12}$. The volume discharge has a much faster temporal variation associated with multiple, discrete microdischarges ${ }^{36}$ but a much smaller spatial variation restricted to one dimension as the plasma expands and contracts within the small air gap.

The 1D case has a simple, exact solution to Poisson's equation describing the pre-breakdown electric field in the air gap that simplifies analysis (e.g., Reference 35, and other basic textbooks under "partially filled capacitor"). The disadvantage of the 1D case is that, due to symmetry, there is no mean, induced momentum flux to use as a diagnostic indicator. In addition, the equilibrium plasma chemistry conditions in the confined space may differ from the asymmetric 2D case where a steady supply of fresh replenishment air is available. Furthermore, the confined space geometry is subject to various plasma instabilities leading to patterned discharge phenomena ${ }^{36}$. Nonetheless, 
the electron and ion energies for the 1D and 2D cases should be similar for same frequency and voltage. By comparing voltage and current relationships for the 1D case for different dielectric materials, it may be possible to detect plasma-surface interaction effects. Also, the 1D case can be readily modeled using commonly available analog circuit simulation software as will be discussed below.

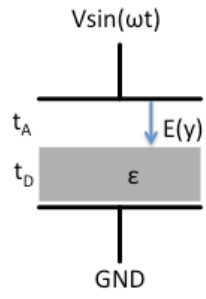

(a)

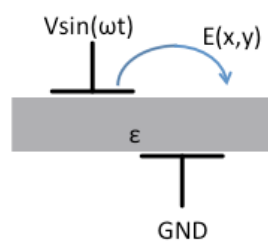

(b)

Figure 17. One-dimensional volume discharge (a) vs. two-dimensional surface discharge (b).

For the 1D case in Figure 17(a), an algebraic expression for voltage on the exposed dielectric surface can be easily derived using Laplace's equation and a capacitive voltage divider. The capacitance of the partially filled capacitor is a commonly used example in many electrical engineering textbooks (e.g., Reference 35, page 148) and the pre-breakdown voltage on the dielectric surface can be shown to be:

$$
\frac{V_{d}}{V_{S}}=\frac{1}{1+\frac{t_{a}}{t_{e f f}}},
$$

where $t_{\text {eff }}$ is the effective thickness, $t_{\text {eff }}=t_{d} / \varepsilon_{r}, t_{d}$ is the dielectric thickness, $\varepsilon_{r}$ is the relative permittivity of the dielectric material.

A schematic representation and photograph of the 1D test apparatus is shown in Figure 18. The large brass electrodes were re-purposed components from the dielectric breakdown tester (Section IIA) and are not the optimal design for this application due to the extensive fringe electric fields at the edges. As shown below, however, the rapid radial decline in electric field outside of the electrodes effectively confines the plasma to the air gap. Lower profile electrodes with guard rings to minimize edge fringe effects may be an improvement but were not investigated. The leveling platen used to create a uniform height air gap is an essential requirement. In order to avoid plasma breakdown in small backside gaps due to thickness non-uniformities of the dielectric material, the top surface of the lower brass electrode was coated with silicone dielectric grease (Permatex Dielectric Tune Up Grease, $\mathrm{p} / \mathrm{n}$ 22058) and pressed firmly into place to act as a temporary viscous adhesive and fill any gaps. A pin on the bottom of the lower electrode maintains its coaxial relation to the upper electrode. A $1 \mathrm{~mm}$ pitch threaded adjusting nut was rotated around the stationary threaded rod to raise and lower the upper electrode in order to precisely set the air gap. Electrical power was applied through the quick-connect cables shown in Figure 18. An example of the device in operation is shown in Figure 19. 

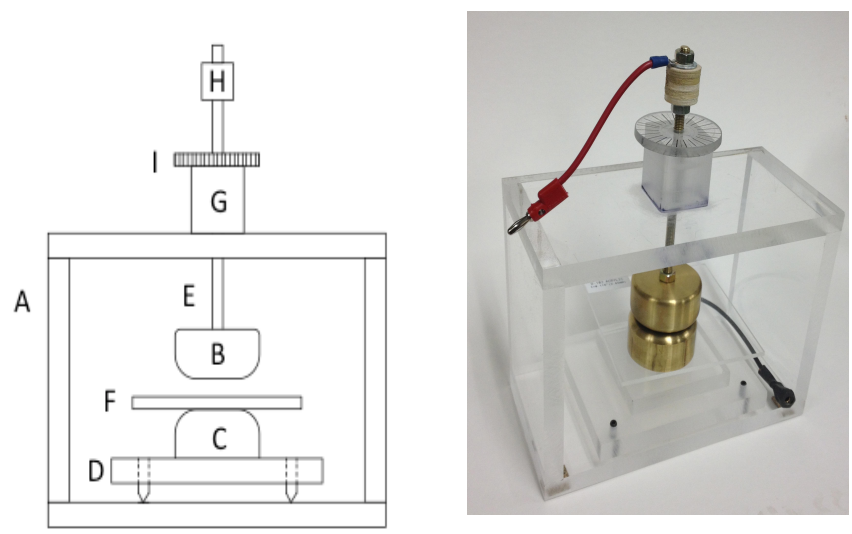

Figure 18. 1-D volume discharge apparatus schematic and photograph. (A. Acrylic plastic frame, B/C, brass electrodes, D, set screw leveling platen, E, brass threaded rod, F, test specimen, G, smooth bore alignment block, $\mathrm{H}$, rotation knob, I, threaded nut and rotation position indicator). The brass electrodes are $50.8 \mathrm{~mm}$ in diameter.

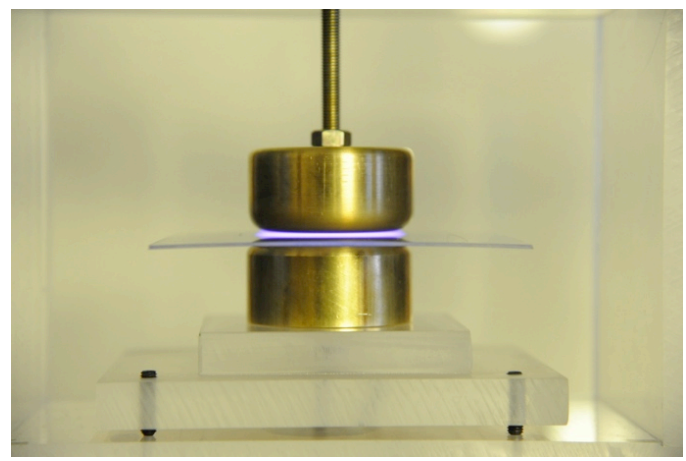

Figure 19. Example of a volumetric DBD discharge viewed on edge. The dielectric is $1 \mathrm{~mm}$ thick acrylic plastic and the air gap is $1 \mathrm{~mm}$. $\mathrm{f}=1 \mathrm{kHz}, \mathrm{V}=20 \mathrm{kV}$.

An effective way to characterize the 1D volume discharge is to use the charge transfer method, described in Reference 37 and the basis of the circuit simulations to follow in this section. This method allows transfer of charge from a physically inaccessible location, in this case on the dielectric surface, to an accessible location, a series probe capacitor. The method is based on the principle that the total charge in a circuit of series-connected capacitors is constant and is given by the simple relation $\mathrm{Q}=\mathrm{CV}$ where $\mathrm{C}$ and $\mathrm{V}$ are the relevant capacitance and voltage respectively. A simplified DBD actuator circuit including the charge transfer probe capacitor is shown in Figure 16 as previously discussed. The parallel elements $C_{a}$ and $R_{a}$ represent the plasma and vary periodically with time as the plasma ignites and extinguishes twice per cycle. Charges on capacitors $C_{a}$ and $C_{d}$ are not easily accessible to measurement. By adding series capacitor, $\mathrm{Cp}$, however, the charge is transferred to an accessible location and easily measured by recording voltage $\mathrm{V}_{\mathrm{p}}$ across known probe capacitor $\mathrm{C}_{\mathrm{p}}$. In the current case, $\mathrm{C}_{\mathrm{p}}$ is a large-valued (i.e., low impedance) capacitor relative to the actuator capacitances $\mathrm{C}_{\mathrm{a}}$ and $\mathrm{C}_{\mathrm{d}}$. For the actuators used in this study, $\mathrm{C}_{\mathrm{a}}$ and $\mathrm{C}_{\mathrm{d}}$ are typically in the low tens of picofarads and the probe capacitor, $\mathrm{C}_{\mathrm{p}}$, was selected as 22 nanofarads or approximately 2000 times lower impedance than the actuator so as not to significantly load or alter the DBD circuit.

An example of the resulting charge transfer waveform for the volume discharge case is shown in Figure 20 . The cyclogram is plotted from phased-averaged voltage waveforms over 128 oscilloscope sweeps. The charge value is linearly related to the probe voltage by $Q=C_{p} V_{p}$ where $C_{p}$ has a fixed value of $22 \mathrm{nF}$. The capacitance of the actuator can easily be determined from the slope of cyclogram charge-voltage waveform for the plasma-on and plasma-off 
segments of the cycle, $C=d Q / d V_{s}=d\left(C_{p} V_{p}\right) / \mathrm{dV}_{s}$. Slope values, $S 1$ and $S 2$, as shown in the figure are provided in the caption. The area enclosed by the cyclogram is equal to the energy dissipated per AC activation cycle. The product of the energy per cycle and the excitation frequency is the dissipated power.

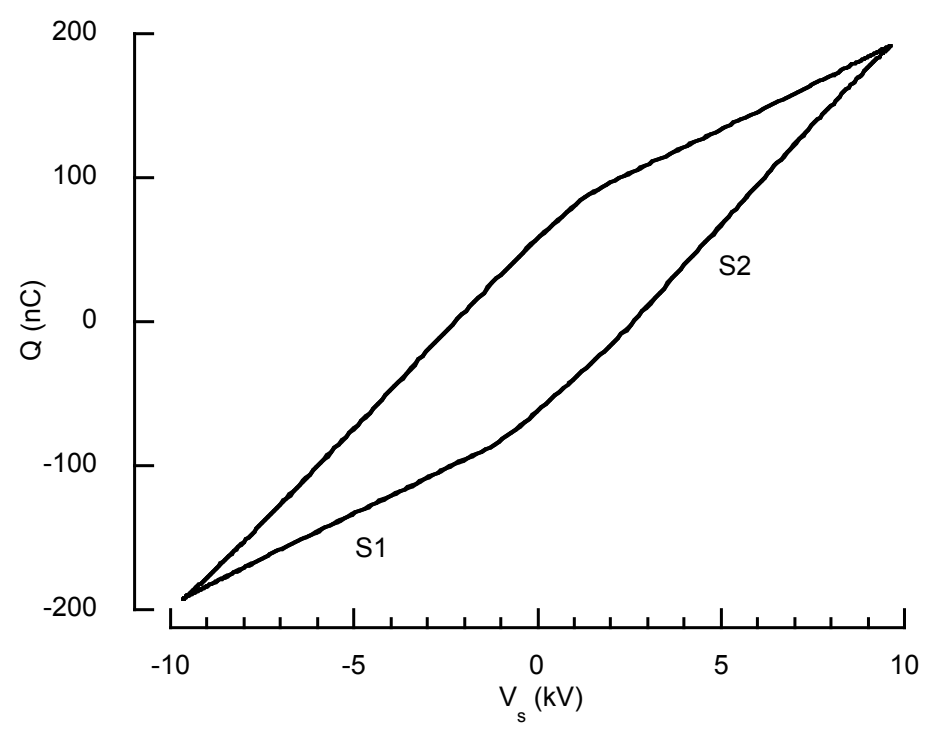

Figure 20. Example of 1D charge transfer method cyclogram (PTFE, $t_{d}=1.07 \mathrm{~mm}, \mathrm{t}_{\mathrm{a}}=1.00 \mathrm{~mm}, \mathrm{f}=1 \mathrm{kHz}, \mathrm{C}_{\mathrm{p}}=22 \mathrm{nF}, \mathrm{S1}=12.63, \mathrm{S2}=27.63 \mathrm{nC} / \mathrm{kV}$ or $\mathrm{pF}$ ).

The 1D and 2D DBD discharges differ somewhat in charging characteristics. In both cases, charge transfer occurs by three methods: 1) dielectric polarization, i.e., the usual capacitor charging mechanism irrespective of plasma formation, 2) discrete microdischarges ${ }^{36}$, and, 3) charge deposition to and from the plasma to the dielectric surface and exposed electrode ${ }^{12}$. The role of the microdischarges is much more evident in the 1D case than in the 2D case. Figures 21 and 22 show brief segments of the total current and charge history for a rising input voltage. In the $1 \mathrm{D}$ case, charge transfer due to discrete microdischarges is clearly evident as small steps in the accumulated charge and, furthermore, are seen to exactly coincide with the spikes in the total current measured with a current transformer on the high voltage side close to the actuator. This observation is consistent with prior investigations of the $1 \mathrm{D}$ volume discharge ${ }^{36}$. In the $2 \mathrm{D}$ actuator case, the influence of the discrete microdischarges is not as evident although some stepwise features in the charge curve seem to be related to spikes in the total current. The microdischarge phenomenon is relevant to plasma behavior in the presence of water vapor (humidity) as described by Falkenstein and Coogan ${ }^{38}$. They show by photographic observation of discrete microdicharges in a volume discharge that the dielectric capacitance increases with the addition of water. Since the surface discharge does not exhibit the same discrete microdischarge behavior, it is not clear that same mechanism applies. From Figure 12, an increase in dielectric capacitance equates to a reduction in effective thickness and one would expect the thrust to increase. As shown in Figure 10, however, change in thrust with water vapor depends upon the dielectric material's water absorption rate. 


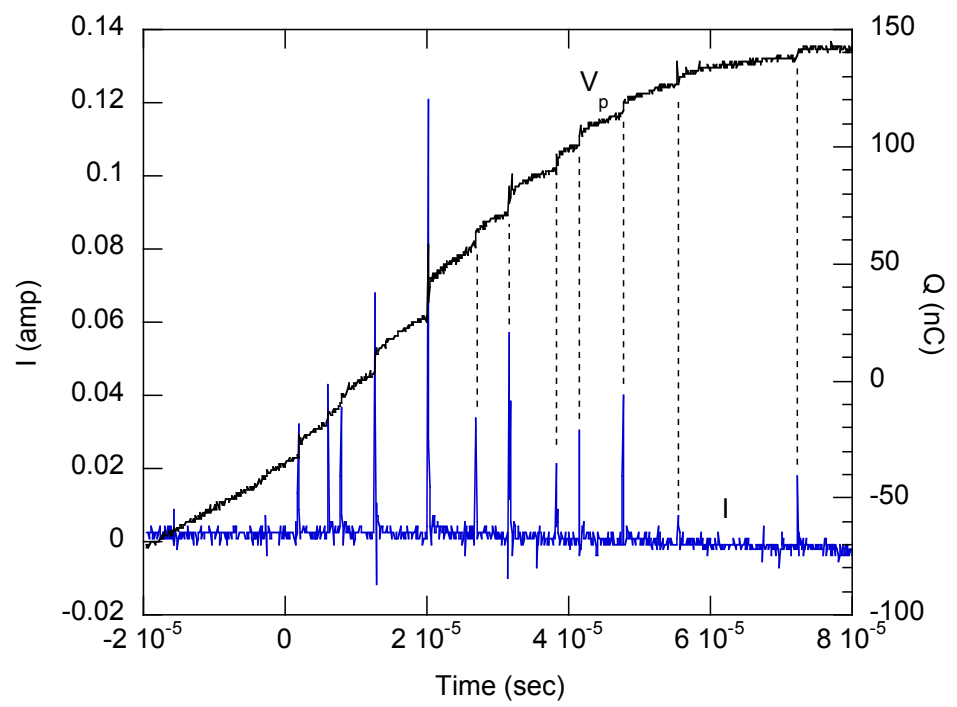

Figure 21. PTFE $t_{d}=1.07 \mathrm{~mm}, t_{a}=1.00 \mathrm{~mm}, f=3 \mathrm{kHz}, \mathrm{V}_{\mathrm{s}}=16 \mathrm{kV} \mathrm{V}_{\mathrm{pp}}$.

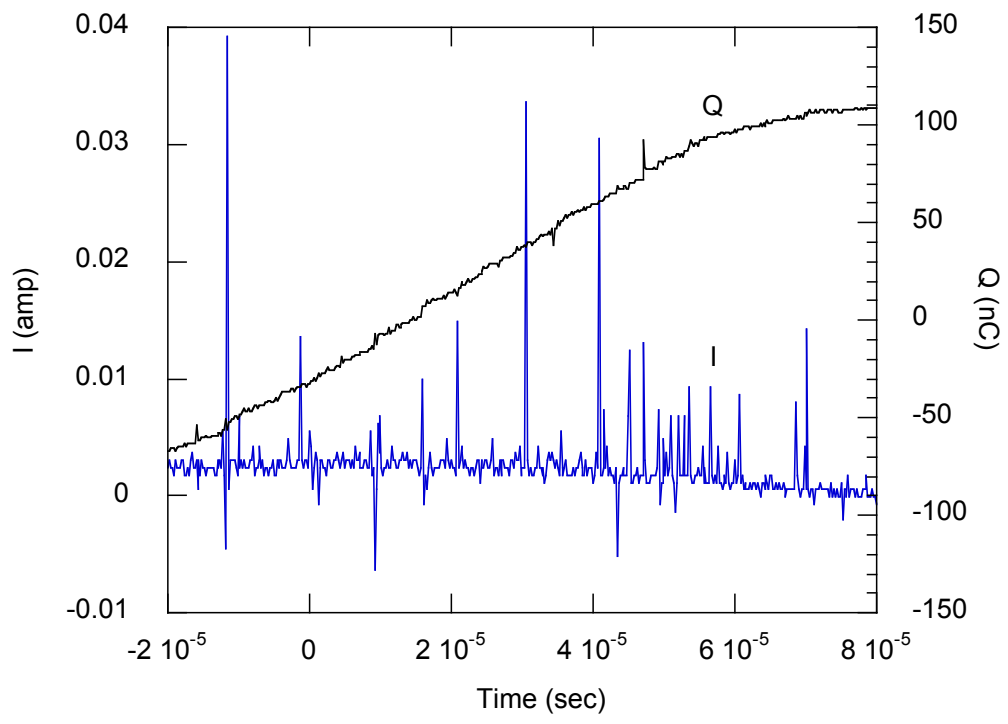

Figure 22. $P$ TFE $t_{d}=1.07 \mathrm{~mm}, \mathrm{f}=3 \mathrm{kHz}, \mathrm{V}_{\mathrm{s}}=16 \mathrm{kV}_{\mathrm{pp}}$.

A series of $1 \mathrm{D}$ tests with different dielectric materials in a variety of thicknesses, air gap widths, input voltages and frequencies was conducted as an adjunct to the 2D actuator thrust measurements to see if any unexplained differences between materials existed that could be the basis for future DBD dielectric material studies 


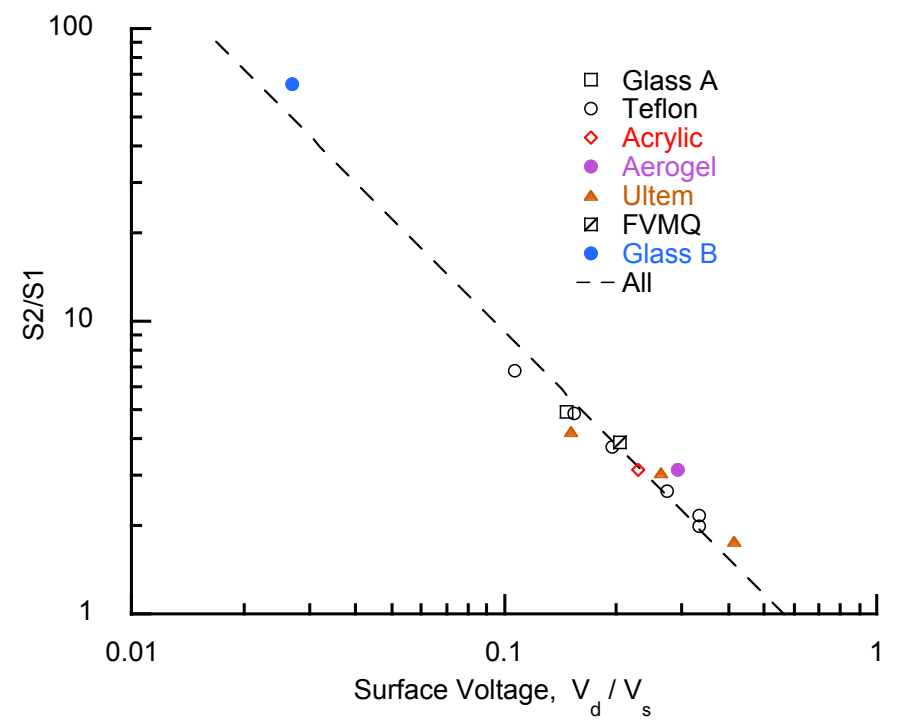

Figure 23. Cyclogram slope ratio vs. computed surface voltage (Equation 9) for different permittivity materials. $t_{a}=1.00 \mathrm{~mm}, f=1 \mathrm{kHz}, V_{s}=20 \mathrm{kV}$.

Figure 23 shows a plot of the ratio of cyclogram plasma-off segment (S1) and plasma-on (S2) segment with respect to computed surface voltage ratio from equation 9 for a range of materials. Since the cyclogram slopes are proportional to capacitance, taking the ratio of the plasma-off and plasma-on slopes effectively removes the influence of the pre-breakdown circuit impedance and displays only the increase in capacitance due to the plasma. As seen, such procedure correlates all of the materials and thicknesses into a single power law. From Equation 9, an increase in abscissa, $V_{d} / V_{s}$ corresponds to an increase in the effective thickness, $t_{d} / \varepsilon_{r}$. Therefore, increased effective thickness leads to reduce plasma-induced capacitance. This is the same mechanism responsible for the reduction in thrust in the 2D case with increasing effective thickness as shown in Figure 11. Based on these results, it can be concluded, therefore, that changes in capacitance due to plasma formation in either the 1D or 2D cases occurs independently of the chemical composition of the different materials. When actuator impedance is properly accounted for, there is no evidence of any surface-plasma interaction such as secondary electron emission or catalytic effects that contribute to plasma-induced capacitance. The chemical composition and structure of the material appear to have little or no impact on charge transfer characteristics when the overall circuit impedance is accounted for.

\section{B. Circuit Simulations}

To further analyze the 1D test data, circuit simulations were made to model the dielectric materials, test environment and plasma. Figure 24 shows the two circuits used to model the 1D experiments. These are based on the simple circuit in Figure 16 with additional elements added to account 


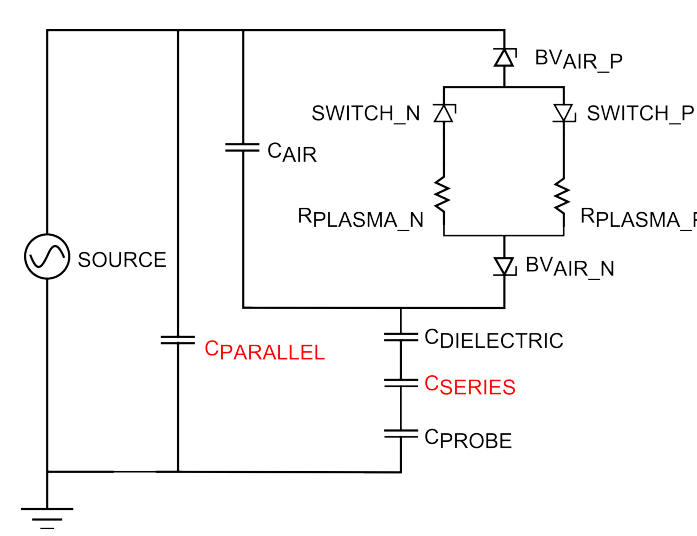

(a) 4-diode model

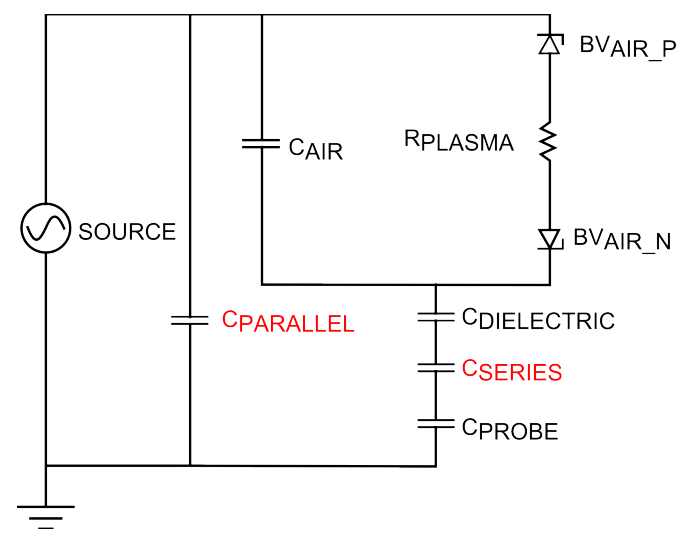

(b) 2-diode model

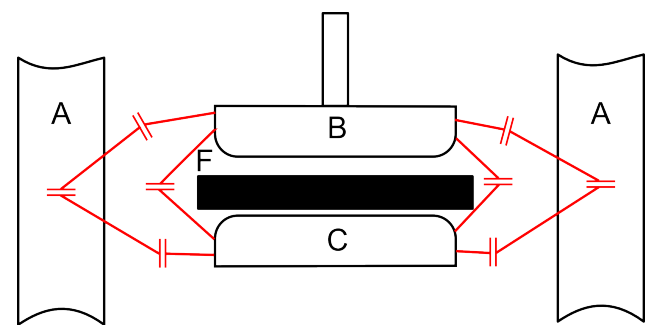

(c) 1D geometry with stray capacitances indicated

Figure 24. The circuits used to simulate the 1D experiments. The circuit elements were chose to represent the dielectric material (F) as well as the test fixture (B, C) and its surroundings (A). These extraneous capacitances are captured as the circuit elements $C_{\text {PARALLEL }}$ and $C_{\text {SERIES }}$.

for the interaction of the test article with its surroundings as well as for the plasma formation. Dielectric breakdown of the air in the 1D gap was modeled with the 2 back-to-back zener diodes. The reverse breakdown voltages started at $3 \mathrm{kV} \times$ gap in $\mathrm{mm}$. In the circuit in Figure 24(a) (4-diode model), two additional diodes SWITCH_P and SWITCH_N were used to model asymmetry of the discharge and plasma properties in the forward and reverse directions, the reverse breakdown voltage of these diodes was set to $100 \mathrm{kV}$, higher than the voltage range of the experiments. The plasma resistance is allowed to be different in the positive and negative going half cycles of the ac waveform. The circuit in Figure 24(b) (2-diode model) assumes the discharge is symmetrical and thus only a single plasma resistance is used and the values of the dielectric breakdown voltages ( $\mathrm{B}_{\text {VAIR_P }}$ and $\mathrm{B}_{\text {VAIR_N }}$ ) are made the same. The voltage across the probe capacitance and total current in the simulations were compared to experiment. Optimization of the values of the circuit elements to match the calculated data to the experiments was made using CIRCOPT, a Python-based program developed for this work, that uses the simulation engines in the Quite universal circuit simulator (Qucs) ${ }^{39}$ and LTSpice ${ }^{40}$ as back ends. In the simulations, the measured (small signal) properties of the dielectric and air gap were used as starting inputs. The procedure for the optimization as implemented by CIRCOPT was as follows:

1. Obtain template netlist

2. Substitute current parameter values into the template

3. Pass it to the circuit simulator

4. Wait on the result or kill the circuit simulator if there is no convergence in a set time

5. Parse the data, if any, from the circuit simulator

6. Calculate the merit function 
7. Set the next set of parameter values

8. Repeat the above until the termination criterion has been reached. There were two termination criteria: no changes in the merit function or a fixed number of iterations being reached.

9. To compare fitting of the data by models with different numbers of parameters (the 2- and 4-diode models), the Akaike information criterion (AIC) ${ }^{41}$ was used. The AIC deals with the trade-off between the goodness of fit of the model and the complexity of the model.

10. Standard deviations of the best fit parameters were estimated using the Bootstrap method ${ }^{42}$

The parameter value optimization in CIRCOPT was made using the Scipy algorithms Nelder-Mead ${ }^{43}$ and Powell ${ }^{44}$.

\section{Circuit Simulation Results}

Best-fit curves and AIC values showed that, in the 1D case, there is no significant asymmetry and both the 2and 4-diode models appeared to fit the data equally well. Therefore only results from the simpler 2-diode model will be discussed further.

Figure 25 shows experimental and calculated voltages and current at $1 \mathrm{kHz}(25 \mathrm{a}, \mathrm{c}, \mathrm{e})$ and $5 \mathrm{kHz}(25 \mathrm{~b}, \mathrm{~d}, \mathrm{f})$ for the polyimide aerogel. It can be seen that the model fits both the current and the voltage quite well at both frequencies. Similar results were also observed at the other test frequencies. The contribution of the various circuit branches to the total current is shown in Figures 25e and f. A steady sine current, with amplitude similar to the current through the air, flows through the parallel capacitance. The current through the air capacitance rises and falls with the formation of the plasma. This is due to changes in the impedance of the plasma branch upon breakdown. 


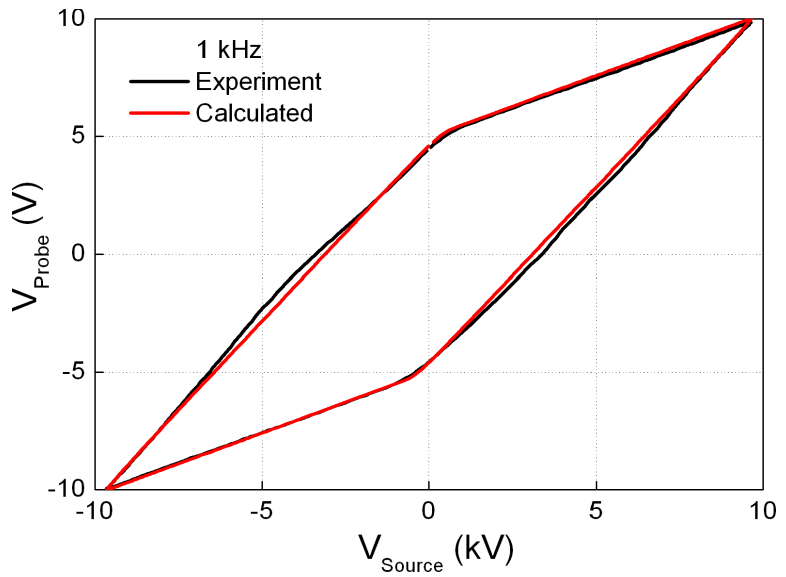

(a)

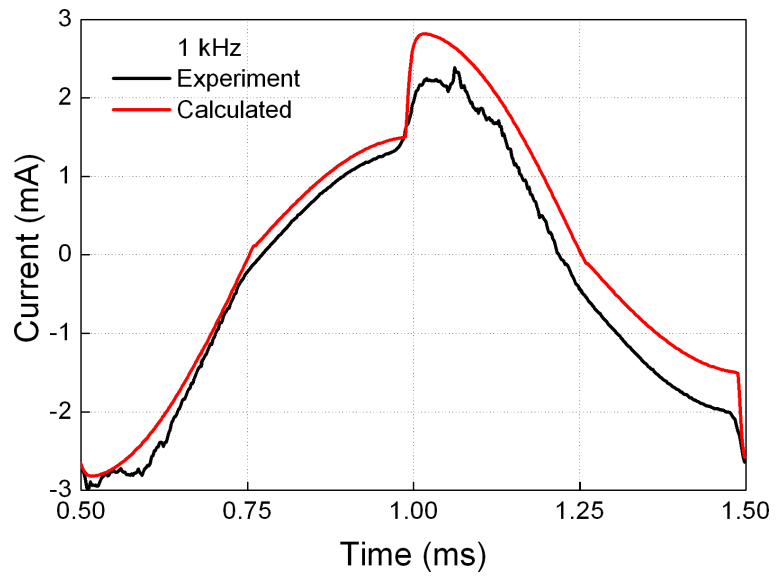

(c)

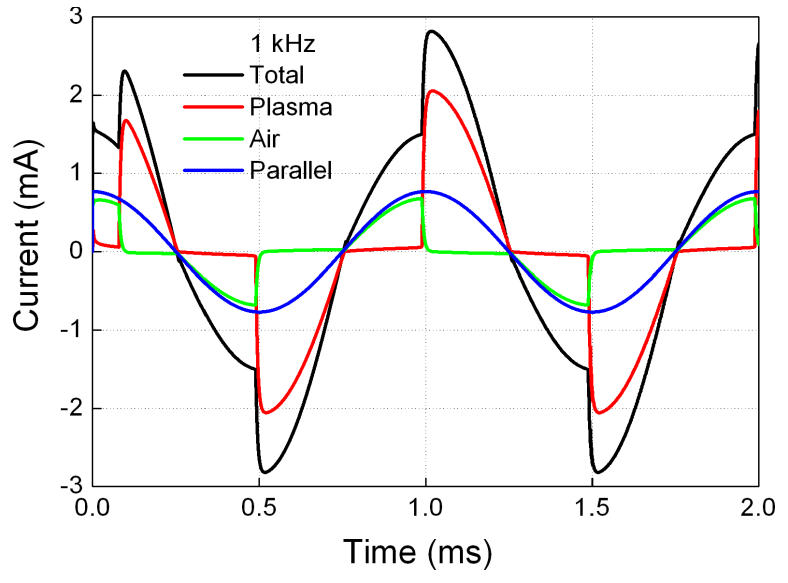

(e)

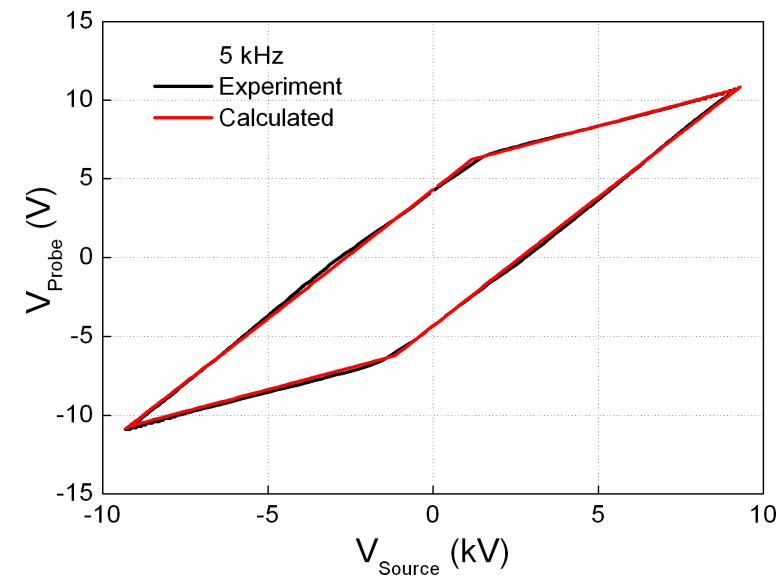

(b)

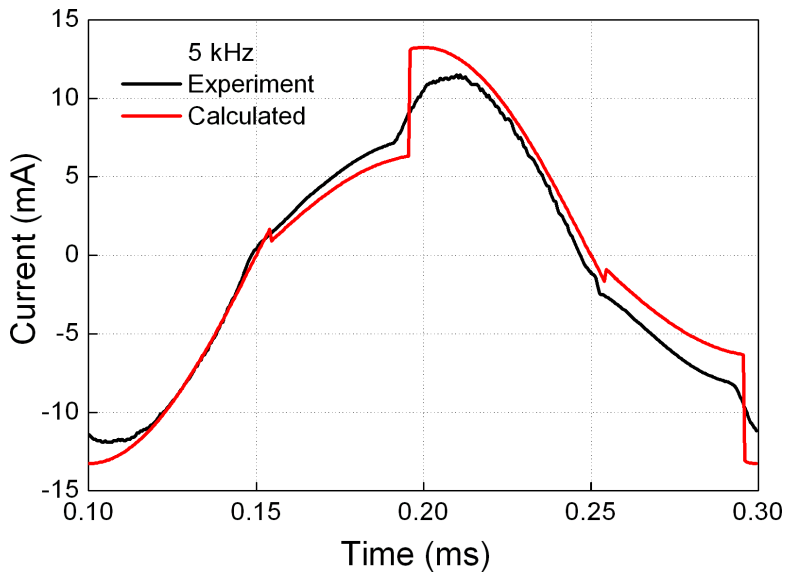

(d)

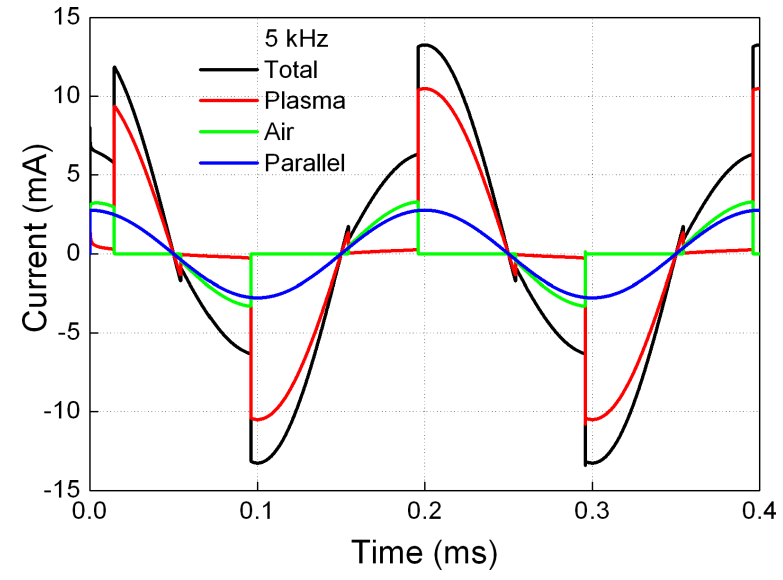

(f)

Figure 25. Typical fitting results showing the experimental voltage and current for the polyimide aerogel at 1 and $5 \mathrm{kHz}$ and values calculated using the 2-diode model (Figure 24(b)). 
Table 3: The best fit values obtained from the circuit simulations. Kept fixed in the analysis and optimization were the diameter of the air gap and dielectric $(50.8 \mathrm{~mm})$, the thickness of the air gap $\left(t_{a}=1.0 \mathrm{~mm}\right)$ and hence the capacitance of the air gap $C_{\text {AIR }}=17.38 \mathrm{pF}\left(\varepsilon_{\mathrm{AIR}}=1\right)$. The probe capacitance was allowed to vary slightly in the region around the $22 \mathrm{nF}$ nominal value $21 \mathrm{nF} \leq$ $\mathrm{C}_{\mathrm{PROBE}} \leq \mathbf{2 3} \mathrm{nF}$. No significant deviation was observed and the best fit values were within a few percent of the nominal value.

\begin{tabular}{|c|c|c|c|c|c|c|}
\hline $\begin{array}{l}\text { Material } \\
\left(t_{d} \mathbf{m m}\right)\end{array}$ & $\begin{array}{c}\text { Frequenc } \\
\mathbf{y} \\
(\mathbf{k H z})\end{array}$ & $\begin{array}{l}\text { BV } \\
(\mathrm{kV})\end{array}$ & $\begin{array}{c}\mathbf{R}_{\text {PLASMA }} \\
(\mathbf{k} \boldsymbol{\Omega})\end{array}$ & $\begin{array}{c}\mathrm{C}_{\text {DIELECTRIC }}(\mathbf{p F}) \\
/ \varepsilon_{\text {DIELECTRIC }}\end{array}$ & $\begin{array}{c}\text { C }_{\text {PARALLEL }} \\
(\text { pF) }\end{array}$ & $\begin{array}{c}\text { C }_{\text {SERIES }} \\
(\mathrm{pF})\end{array}$ \\
\hline \multirow{4}{*}{$\begin{array}{c}\text { Aerogel } \\
(\mathbf{0 . 4 3 )}\end{array}$} & 1 & 2.90 & 107 & $51.1 / 1.26$ & 12.6 & 104 \\
\hline & 2 & 2.84 & 36 & $48.5 / 1.20$ & 13.2 & 109 \\
\hline & 4 & 2.77 & 37 & $48.9 / 1.21$ & 11.4 & 130 \\
\hline & 5 & 2.64 & 0.03 & $48.6 / 1.20$ & 9.5 & 138 \\
\hline \multirow{4}{*}{$\begin{array}{l}\text { PTFE } \\
(1.04)\end{array}$} & 1 & 2.26 & 1.77 & $34.7 / 2.08$ & 13.4 & 86 \\
\hline & 2 & 2.18 & 2.53 & $33.8 / 2.03$ & 13.1 & 105 \\
\hline & 4 & 2.18 & 0.02 & $33.2 / 1.99$ & 11.8 & 175 \\
\hline & 5 & 2.18 & 0.44 & $33.2 / 1.99$ & 11.0 & 226 \\
\hline \multirow{4}{*}{$\begin{array}{c}\text { Acrylic } \\
\text { (0.94) }\end{array}$} & 1 & 2.84 & 0.51 & $59.4 / 3.22$ & 13.1 & 122 \\
\hline & 2 & 2.60 & 0.03 & $59.6 / 3.23$ & 12.4 & 123 \\
\hline & 4 & 2.38 & 21.4 & $51.8 / 2.80$ & 13.5 & 166 \\
\hline & 5 & 2.26 & 1.13 & $55.0 / 2.98$ & 12.0 & 139 \\
\hline \multirow{4}{*}{$\begin{array}{c}\text { FVMQ } \\
\text { (1.47) }\end{array}$} & 1 & 3.13 & 6.90 & $68.7 / 5.83$ & 8.9 & 173 \\
\hline & 2 & 2.92 & 12.5 & $72.1 / 6.12$ & 7.5 & 165 \\
\hline & 4 & 2.61 & 16.1 & $68.5 / 5.81$ & 3.3 & 195 \\
\hline & 5 & 2.49 & 0.45 & $68.6 / 5.82$ & 0.017 & 197 \\
\hline \multirow{4}{*}{$\begin{array}{l}\text { Glass } \\
(1.37)\end{array}$} & 1 & 3.27 & 37.8 & $108 / 8.57$ & 3.3 & 185 \\
\hline & 2 & 2.70 & 0.06 & $101 / 8.01$ & $5.2 \mathrm{E}-6$ & 218 \\
\hline & 4 & 2.26 & 0.029 & $103 / 8.17$ & 10.11 & 212 \\
\hline & 5 & 2.18 & 0.006 & $104 / 8.20$ & $2.8 \mathrm{E}-4$ & 205 \\
\hline
\end{tabular}




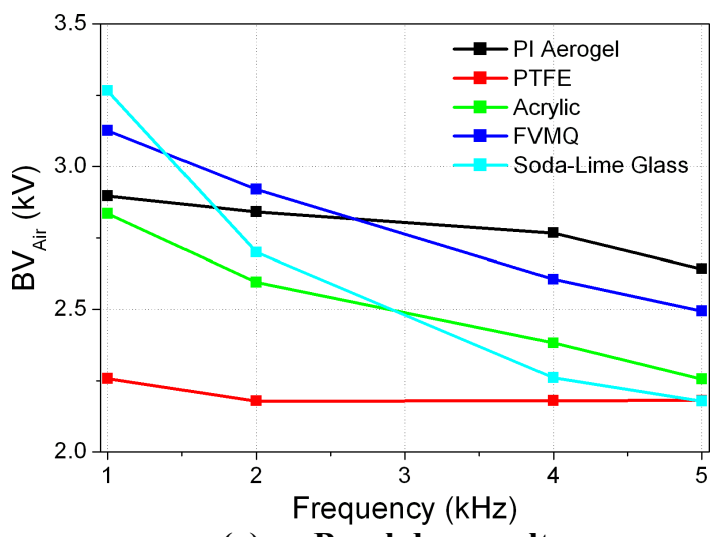

(a) Breakdown voltage

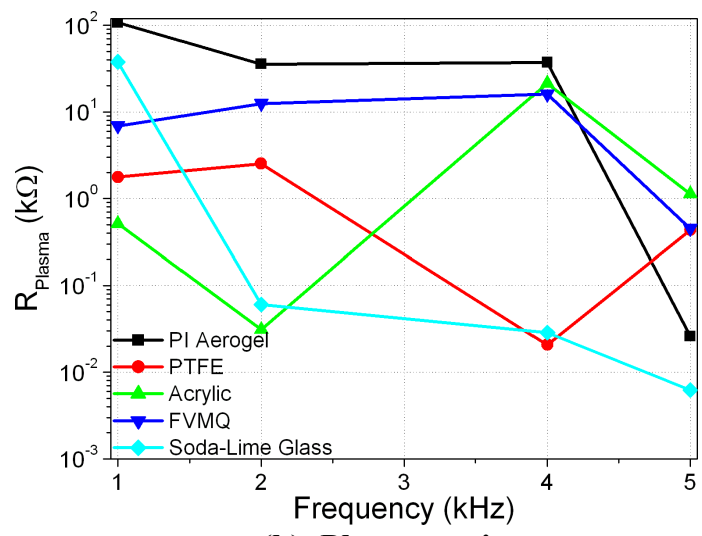

(b) Plasma resistance

Figure 26. The best-fit diode breakdown voltages and plasma resistances obtained from the circuit in Fig. 24(b). Estimates of the standard deviations of the parameters computed using the Bootstrap method were very small.

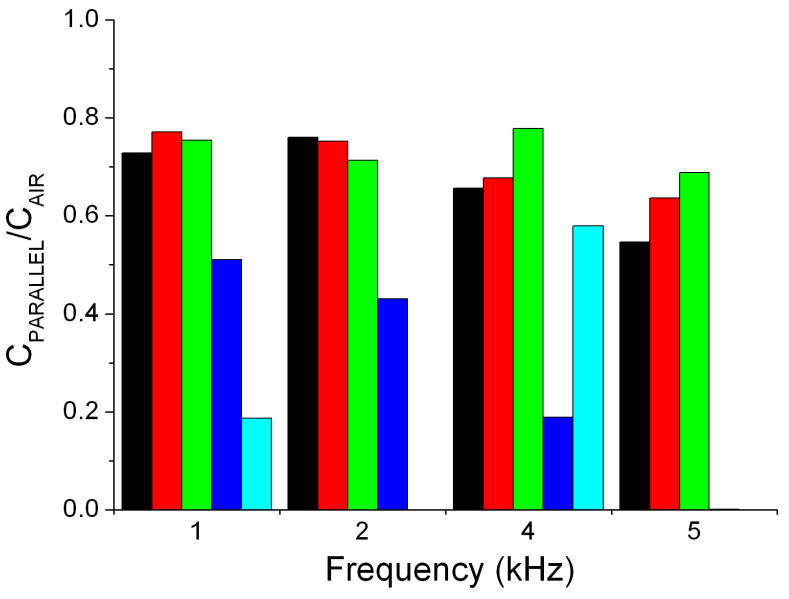

(a) Parallel capacitance

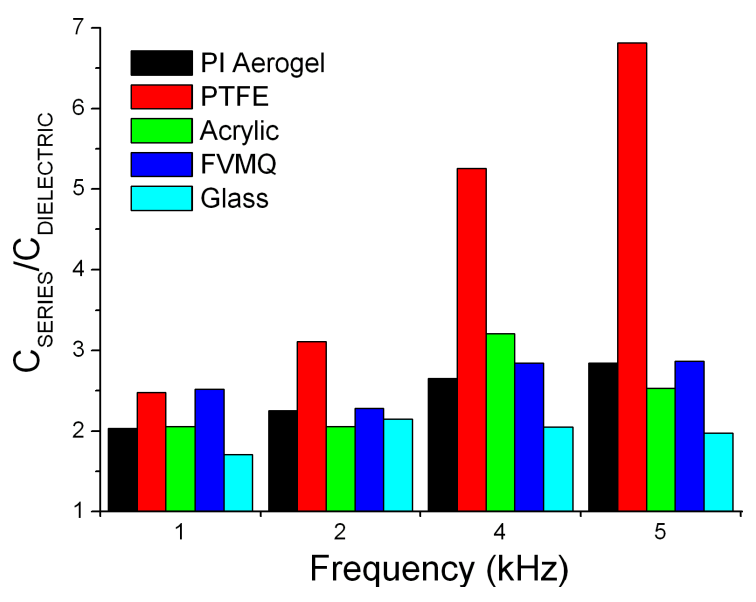

(b) Series capacitance

Figure 27. Trends in the capacitances $C_{\text {PARALlEL }}$ and $\mathrm{C}_{\text {SERIES }}$

A full set of the best fit parameters values from the circuit simulations and optimization is given in Table 3 .

Figure 26 shows the best-fit reverse breakdown voltage of the zener diodes (26a) and the plasma resistance (26b). The breakdown voltages lie in a narrow range and all decrease slightly with increasing frequency as expected. The plasma resistances vary by several orders of magnitude. This is in spite of the very small standard deviations in the best-fit parameter values calculated using the Bootstrap method and which may be in part due to the symmetry of the waveforms. Values of $R_{\text {PLASMA }}$ above $500 \mathrm{k} \Omega$ caused significant rounding of the voltage cyclograms that is inconsistent with the experimental observations thus placing an upper bound. Figure 27 shows the ratios of the capacitances $\mathrm{C}_{\text {PARALLEL }}$ and $\mathrm{C}_{\text {SERIES }}$ to $\mathrm{C}_{\text {AIR }}$ and $\mathrm{C}_{\text {DIELECTRIC }}$ respectively. $\mathrm{C}_{\text {PARAllel }}$ is about $0.6 \times \mathrm{C}_{\text {AIR }}$ while $\mathrm{C}_{\text {SERIES }}$

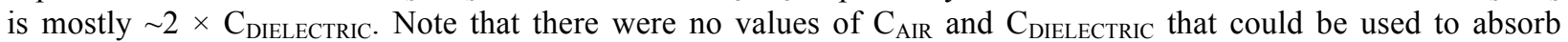
$\mathrm{C}_{\text {PARALLEL }}$ or $\mathrm{C}_{\text {SERIES }}$ thus simplifying the circuit while remaining consistent with the known properties of the materials. The capacitance $\mathrm{C}_{\text {SERIES }}$ may be a combination of the contributions of the test setup as well as nonlinearity of the permittivity of the dielectric at the $1 \mathrm{D}$ test voltages which are much greater than the $1 \mathrm{~V}$ where the material dielectric constants were measured. 


\section{Summary and Conclusions}

A cross-disiplinary study of DBD actuator dielectric materials was conducted in search of material optimization opportunities to improve DBD actuator performance. The rationale was to study a variety of existing dielectric materials, along with new polyimide aerogels, seeking to explain differences in performance based on both volume and surface properties. The primary diagnostic methods employed were static thrust stand measurements of asymmetric, surface-discharge actuators and charge-transfer studies on one-dimesional volume-discharge actuators. Low voltage dielectric property measurements (permittivity and loss-tangent) were conducted in accordance with ASTM standards. Open-source circuit simulation software was configured to find optimal, lumped-parameter values for simplified circuit represenations of the $1 \mathrm{D}$ volume discharge showing good correspondence to experiment data provided that stray capacitance is accounted for.

The induced thrust for a range of relative dielectric permittivities and thicknesses covering nearly an order of magnitude was found to scale semi-logarithmically with the effective dielectric thickness (ratio of thickness to dielectric constant) at constant input voltage. The semi-logarithmic behavior was shown to be predicted by an approximate, method-of-images analysis of the pre-breakdown capacitance from which it was concluded that thrust depends primarily on DBD circuit impedance, all other factors held constant. For the range of input voltages tested $(<20 \mathrm{kVpp})$, this finding effectively rules out any significant role of plasma-surface interactions, such as secondary electron emision from the dielectric or surface catalytic effects, in DBD thrust production. Based in this finding, it is concluded that chemical composition and structure of the material has no significant effect on DBD performance, at least for the range of input energies tested.

In the course of the studies, it became apparent that normal levels of atmospheric humidity can have a significant effect on DBD performance when accurate thrust measurements are required, as, for example, in the case of CFD code-validation studies. This became most apparent in our observation of a wide variation of DBD thrust readings when testing surface coatings such as photocatalytic titanium oxide and various surfactants and antioxidants. This necessitated the postponement of the surface coating portion of the study pending development of proper humidity control and testing protocol. Humidity tests on uncoated PTFE and Nylon were conducted showing large variations in both thrust levels and trends. This behavior is presumably due to the large difference in water absorption rate for the PTFE and Nylon and helps to identify requirements for future research in this area.

An extensive study of one-dimensional volume discharges was conducted, both experimentally and analytically, using the charge-transfer cyclogram (Lissajous) method. The charge-transfer method circumvents error-prone thrust measurements at the expense of a different model geometry (1D vs. 2D), lack of mean, directed momentum transfer, and possibly creating different microdischarge physics within the air gap (patterned discharges, discharge instabilities). It provides, however, a simple, alternative method by which to study dielectric materials, surface coatings, and ambient gas properties under discharge energy levels very close to the $2 \mathrm{D}$ surface-discharge case. The key finding of the current study was that the cyclogram plasma-on to plasma-off slope ratio $\left(\mathrm{S}_{2} / \mathrm{S}_{1}\right)$, indicative of the increase in air gap charge due to the plasma, varies logrithmically with the effective dielectric thickness $\left(t_{d} / \varepsilon_{r}\right)$ and independently of the chemical composition of the dielectric material. This finding shows that the charge increase depends only on the effective dielectric thickness, and not the dielectric material's chemical composition and that the the slope variation is solely a pre-breakdown capacitive impedance effect.

The 1D cyclogram data was analyzed using analog, SPICE3-based ${ }^{39,40}$, open-source, circuit simulation software in order to find the effective plasma resistances and capacitances that best fit the experimental waveforms. In order to match the simulations to the experiment, it was necessary to include iteration on stray capacitance between the 1D electrodes, and between the individual electrodes and the laboratory surroundings. The search procedure resulted in good reproduction of experimental waveforms. This finding suggests that the fitting method can become the basis for devlopment of a semi-empirical plasma actuator design method. The requirement for inclusion of stray capacitance has implications for the 2D surface-discharge thrust measurement case. It is likely that different laboratory apparatuses will have different stray capacitances and, therefore, different thrust readings based on the overall circuit response to the excitation voltage. This represents a source of uncertainty when comparing 2D surface-discharge thrust data between different laboratories, even on identical models with important implications for acquisition of CFD code-validation data. 


\section{Acknowledgments}

This work was funded under the NASA Aeronautics Research Mission Directorate (ARMD) 2011 Phase 1 and 2012 Phase 2 Seedling Fund awards. The authors would like to acknowledge Mr. Cameron Butler (University of Virginia) for his contributions to the $\mathrm{dBt}$ dielectric break down test software.

\section{References}

${ }^{1}$ Takashima,K., Zuzeek, Y., Lempert,W.R., and Adamovich, I.V., "Characterization of Surface Dielectric Barrier Discharge Plasma Sustained by Repetitive Nanosecond Pulses", AIAA Paper 2010-4764.

${ }^{2}$ Likhanskii, A.V., Shneider M.N., Macheret S.O, Miles R.B., "Modeling of dielectric barrier discharge plasma actuators driven by repetitive nanosecond pulses", 2007 Physics of Plasmas 14, 073501.

${ }^{3}$ Opaits, D.F., "Dielectric Barrier Discharge Plasma Actuator for Flow Control", Final Report, NASA CR 2012217655, September, 2012.

${ }^{4}$ Moreau E., "Airflow control by non-thermal plasma actuators", J. Phys D: Appl. Phys., V. 40, N. 3, 2007, pp. 605636.

${ }^{5}$ Corke T.C., Enloe C.L., and Wilkinson S.P., "Dielectric barrier discharge plasma actuators for flow control", Ann. Rev. Fluid Mech. V. 42, 2010, pp: 505-529.

${ }^{6}$ Roth, J.R., Sherman, D.M., and Wilkinson, S.P., "Boundary Layer Flow Control With A One Atmosphere Uniform Glow Discharge Surface Plasma", AIAA Paper 1998-0328.

${ }^{7}$ Zito,J.C., Durscher,R.J., Soni,J., Roy,S. and Arnold, P.A., "Flow and force inducement using micron size dielectric barrier discharge actuators", Appl. Phys. Lett. 100, 193502, 2012.

${ }^{8}$ Macheret,S.O., Shneider,M.N., and Miles, R.B., "Magnetohydrodynamic and Electrohydrodynamic Control of Hypersonic Flows of Weakly Ionized Plasmas", AIAA J., Vol. 42, No. 7, July 2004, pp. 1378-1387.

${ }^{9}$ Roth, J. R., Industrial Plasma Engineering, Volume 1 - Principles, Institute of Physics Publishing, Bristol and Philadelphia, ISBN 0-7503-0318-2, 1995 , p. 149.

${ }^{10}$ Hayt, W.H. Jr., Engineering Electromagnetics, 5th Ed. , McGraw-Hill, Inc., ISBN 0-07-027406-1, 1989, pp. $147-$ 150.

${ }^{11}$ Enloe, C.L., McLaughlin. T.E., Gregory, J.W., Medina, R.A., and Miller. W.S., "Surface Potential and Electric Field Structure in the Aerodynamic Plasma Actuator", AIAA Paper 2008-1103, Jan. 2008.

${ }^{12}$ Enloe, C.L., Font, G.I., McLaughlin, T.E., and Orlov, D.M., "Surface Potential and Longitudinal Electric Field Measurements in the Aerodynamic Plasma Actuator", AIAA J., Vol. 46, No. 11, November 2008, pp. 2730-2740.

${ }^{13}$ Massines, F.;Ben Gadri, R.;Rabehi, A.; Decomps, Ph.; Segur, P.; and, Mayoux, Ch., "Mechanisms of a Glow Discharge at Atmospheric Pressure Controlled by Dielectric Barrier", Journal of Applied Physics, Vol. 83, No. 6, March, 1998, pp. 2950-2957.

${ }^{14}$ Handbook of Chemistry and Physics, Lide, D.R. ed., $73^{\text {rd }}$ Edition, Special Student Edition, 1992-1993, CRC Press, ISBN 0-8493-0566-7, page 12-110.

${ }^{15}$ Starikovskiy,A. and Miles,R., "Dielectric Barrier Discharge Control and Flow Acceleration Enhancement by Diode Surface", AIAA Paper 2013-0754, 2013.

${ }^{16}$ Anderson, R. and Roy, S., "Preliminary Experiments of Barrier Discharge Plasma Actuators using Dry and Humid Air", AIAA Paper 2006-369, 2006.

${ }^{17}$ Benard, N., Balcon, N., and Moreau, E., "Electric Wind Produced by a Surface Dielectric Barrier Discharge Operating Over a Wide Range of Relative Humidity", AIAA 2009-488, 2009.

${ }^{18}$ Bartnikas, R., "Partial Discharges Their Mechanism Detection and Measurement, IEEE Trans. on Dielectrics and Electrical Insulation", v. 9, n. 5, Oct. 2002, pp. 763-808.

${ }^{19}$ Guo, H., Meador, M.A.B., McCorkle, L., Quade, D.J., Guo, J., Hamilton, B., and Cakmak, M., " Tailoring 
properties of cross-linked polyimide aerogels for better moisture resistance, flexibility and strength", ACS Applied Materials and Interfaces, 2014, 5422-5429.

${ }^{20}$ Meador, M.A.B., McMillon, E., Sandberg, A., Barrios,E., Wilmoth, N.G., Mueller,C.H., and Miranda, F.A., "Dielectric and Other Properties of Polyimide Aerogels Containing Fluorinated Blocks", ACS Applied Materials and Interfaces, January 31, 2014, DOI:10.1021/am405106h.

${ }^{21}$ Durscher, R. and Roy, S., "Aerogel and ferroelectric dielectric materials for plasma actuators", J. Phys. D: Appl. Phys. 45 (2012) 012001

${ }^{22}$ Fine N., and Brickner S., "Plasma catalysis for enhanced-thrust single dielectric barrier discharge plasma actuators", AIAA Journal, vol.48 no.12, 2010, pp. 2979-2982.

${ }^{23}$ Baytekin H. T., Baytekin B., Hermans T.M., Kowalczyk B., Grzybowski B.A., Control of surface charges by radicals as a principle of antistatic polymers protecting electronic circuitry, Science, Vol. 341, 20 September 2013, pp. $1368-1371$

${ }^{24}$ ASTM D149, Standard Test Method for Dielectric Breakdown Voltage and Dielectric Strength of Solid Electrical Insulating Materials at Commercial Power Frequencies, 2013

${ }^{25}$ ASTM D638-10, Standard Test Method for Tensile Properties of Plastics, 2010.

${ }^{26}$ ASTM D1708-13, Standard Test Method for Tensile Properties of Plastics by Use of Microtensile Specimens, 2013.

${ }^{27}$ Dyre, J. C., \& Schrøder, T. B. (2000), "Universality of ac conduction in disodered solids", Review of Modern Physics, 72(3), 873-892.

${ }^{28}$ Hrubesh, L.W. and Pekala, R.W., "Dielectric properties and electronic applications of aerogels", Lawrence Livermore National Laboratory Report UCRL-JC-113378, CONF-9308158-2, presented at International Symposium on Advances in Sol-Gel Processing and Applications, Chicago, Illinois, August 24-28, 1993.

${ }^{29}$ David E. Ashpis Matthew C. Laun, "Dielectric Barrier Discharge (DBD) Plasma Actuators Thrust - Measurement Methodology Incorporating New Anti-Thrust Hypothesis", AIAA Paper 2014-0486, 2014.

${ }^{30}$ Kwok, P.L.C., Trietsch, S.J., Kumon,M. and Hak-Kim Chan,H.-K., "Electrostatic Charge Characteristics of Jet Nebulized Aerosols", J. Aerosol Medicine and Pulmonary Drug Delivery Volume 23, Number 3, 2010.

${ }^{31}$ ASTM D-570 -98, Standard Test Method for Water Absorption of Plastics, 2010

${ }^{32}$ Attwood, S.S., Electric and Magnetic Fields, 3rd Edition, John Wiley \& Sons, Inc, New York, 1949, pp 141-144 (out-of-print). See also Dover Publication edition, 1967, ISBN 048661753X or 978-0486617534 (out-of-print).

${ }^{33}$ Wheeler, H.A., "Transmission-line properties of a strip on a dielectric sheet on a plane", IEEE Trans. on Microwave Theory and Technique, Vol. MMT-25, No. 8, August 1977, pp. 631-647.

${ }^{34}$ Enloe, C.L., McLaughlin, T.E., VanDyken, K.D. and Kachner, K.D., Jumper, E.J., and Corke, T.C., "Mechanisms and Responses of a single dielectric barrier discharge", AIAA Paper 2003-1021

${ }^{35}$ Hayt, W.H. Jr., Engineering Electromagnetics, 5th Ed. , McGraw-Hill, Inc., ISBN 0-07-027406-1, 1989, pp. $147-$ 150.

${ }^{36}$ Kogelschatz U., "Filamentary, patterned, and diffuse barrier discharges", IEEE Transactions on Plasma Science, vol. 30, no. 4, August 2002, pp. 1400-1408.

${ }^{37}$ Kriegseis J., Möller B., Grundmann S., Tropea C., "Capacitance and power consumption quantification of dielectric barrier discharge (DBD) plasma actuators", Journal of Electrostatics 69 (2011), pp. 302-312.

${ }^{38}$ Falkenstein, Z. and Coogan,J.J., "Microdischarge behaviour in the silent discharge of nitrogen-oxygen and water-air mixtures", J. Phys. D: Appl. Phys. 30 (1997), pp. 817-825.

${ }^{39}$ QucsTeam. (n.d.). Qucs (Quite universal circuit simulator). Retrieved from http://qucs.sourceforge.net/.

${ }^{40}$ Linear Technology. (n.d.). Linear Technology/Software. Retrieved from http://www.linear.com /designtools/software/. 
${ }^{41}$ Akaike, H., "A new look at the statistical model identification", IEEE Transactions on Automatic Control, 19(6), 1974, pp. 716-723.

${ }^{42}$ Press, W. H., Teukolsky, S. A., Vetterling, W. T., and Flannery B. P., Numerical Recipies in $C++, 2^{\text {nd }}$ edition, Cambridge University Press, 2003.

${ }^{43}$ Nelder, J. A., "A simplex method for function minimization", Computer Journal, 7, 1965, pp.308-313.

${ }^{44}$ Powell, M. J., "On Search Directions for Minimization Algorithms", Mathematical Programming, 4, 1973, pp. 193-201. 